\title{
Compressive behavior of FRP-confined concrete-filled PVC tubular columns
}

\author{
Mostafa Fakharifar ${ }^{1}$, Ph.D. and Genda Chen ${ }^{2, *}$, Ph.D., P.E. \\ ${ }^{1}$ Research Assistant, Department of Civil, Architectural and Environmental Engineering, Missouri \\ University of Science and Technology, 209 Pine Building, 1304 N. Pine St., Rolla, MO 65401, Email: \\ $\underline{\text { mfhdc@mst.edu }}$ \\ 2,* (Corresponding Author) Professor and Abbett Distinguished Chair in Civil Engineering, Missouri \\ University of Science and Technology, 328 Butler-Carlton Hall, 1401 N. Pine St., Rolla, MO 65401, Phone: 573- \\ 341-4462, Email: gchen@mst.edu
}

\begin{abstract}
:
This paper presents a new composite confinement system of FRP wrap and PVC tube with and without an impact absorption medium (compressible foam) in between. The compressive behavior of the proposed FRP-confined concrete filled PVC tube (CCFPT) was investigated and compared with those of the concrete filled PVC tube (CFPT) and FRP-wrapped (FW) concrete cylinder. The effect of compressible foam on the post-peak behavior of the CCFPT specimen was explored. The applicability of seven existing FRP-confined stress-strain relationships to predict the ultimate strength and ductility enhancement of FW and CCFPT specimens was evaluated. A total of $14 \mathrm{FW}, 5$ CFPT, and 17 CCFPT specimens with $152 \mathrm{~mm}$ in diameter and $305 \mathrm{~mm}$ in height were tested under monotonically increasing axial loads in compression. The key parameters examined included the type and thickness of FRP wraps, the presence and thickness of compressible foam, and loading area. Test results indicated that, without compressible foam, the CCFPT cylinders resembled the FW cylinders in stress-strain relationships with brittle failures upon FRP rupture and immediately-followed PVC fracture due to sudden transfer in confining pressure. With compressible foam, the CCFPT cylinders can combine the strength of the FW cylinders and the ductility of the CFPT cylinders.
\end{abstract}

Keywords: FRP-confined concrete; FRP-confined concrete-filled PVC tube; Strength; Mechanical testing; confinement. 


\section{1- Introduction}

It has been well established that both the mechanical (strength, stiffness and ductility) and long term performance (durability) of concrete structures (normal strength [1-13], high/ultra-high strength [1420], self-consolidating/compacting [21, 22] and more recently recycled aggregate concrete [23, 24]) can be enhanced through the lateral confinement by a confining jacket (i.e., active or passive confinement) $[25,26]$. Various forms of confining jackets from different materials have been extensively studied for strengthening/rehabilitation of existing structures and for new constructions [27-46], including steel stirrups, steel spirals, hollow tubes/prisms, prestressing strands, fiber reinforced polymer (FRP) composite stirrups, FRP tubes, FRP rings, pre/post-tensioned FRP shells, composite ropes, shape memory alloy (SMA) wraps, and hybrid (active and passive) confining jackets [31, 32, 35, 41, 44, 47-50].

Past studies have demonstrated the enhanced structural performance of concrete filled tube (CFT) systems with steel or FRP confinement as an improved form of gravitational and lateral load resisting system for tall buildings/bridge columns and pile-footings [10, 15-20, 23, 37, 51-55]. Concrete filled steel tube (CFST) and concrete filled FRP tube (CFFT) columns are the two most common types of CFT systems that have been investigated at both member and system levels under static and simulated seismic loading conditions (e.g. [3-5, 10, 14-20, 22, 24, 37, 51, 52]). The CFT systems demonstrated remarkable properties in terms of enhanced structural performance (i.e., strength, stiffness, ductility and hysteretic capacity) and project economy/constructability (e.g. reduced tube thickness due to the composite action between concrete and confining tube [56]). While a steel tube serves as shoring system/permanent formwork and provides substantial continuous confining pressure to the concrete infill $[16,37,51,52]$, the encased concrete can improve fire resistance of the steel tube. Other studies also demonstrated the improved performance of hybrid tubular columns by incorporating steel and FRP tubes, referred to as hybrid double-skin tubular columns or beams with remarkable hysteresis capacity against seismic excitations [57-60]. 
Durability of reinforced concrete (RC) structures and steel-concrete composite structures under severe environmental conditions (e.g. marine environments) has always been a major concern [61, 62]. It was estimated that the U.S. alone annually spent over $\$ 1$ billion for repair and replacement of waterfront piling systems [63]. This high cost has spurred great interest in alternative composite column/pile materials such as FRPs, recycled plastics, and hybrid materials. Consequently, FRP materials were considered an attractive alternative for structures in marine and other harsh environments [6].

Considering the corrosion-induced durability of steel tubes $[14,63]$ and bond issues as well as the brittle failure of elastic FRP tubes, particularly in seismically active regions $[2,16,64,65]$, several studies have been conducted on commercially available thermoplastic pipes, such as high-density polyethylene (HDPE) and polyvinyl chloride (PVC) [62, 66-71] for the improved durability of RC structures. PVC materials, exhibiting remarkable mechanical properties compared to other general purpose olefin plastics, demonstrate impressive ratio of cost to performance, specifically durability [66, 67, 71]. PVC is a polymer-based material which is vastly utilized in the construction industry. Investigation on soil buried PVC pipes after 60 years of active use [72] indicated no deterioration and likely to have a further life expectancy of 50 years. PVC is one of the most important commercial plastics owing to its wide applications, low costs and excellent properties such as (1) high electrical insulation; (2) high resistance for abrasion; (3) low diffusion for humidity; (4) remarkable resistance to water, bases, acids, alcohols, oils; (5) large elongation at break (i.e., ductile); (6) low creep deformation; (7) workability including (e.g. machining, cutting, welding/gluing for fabrication versatility); (8) consistency; and (9) excellent corrosion resistant, durability and mechanical stability (little change in mechanical strength and molecular structure) [73-75]. The thermal conductivity of PVC is only $0.45 \sim 0.6 \%$ of a steel tube, which provides a stable curing condition for the core concrete to achieve high performance and high durability $[70,71]$. Kurt [66] made the first attempt in implementing commercially available rigid plastic (acrylonitrile butadiene styrene and PVC) pipes filled with concrete as a new composite column system for structural applications. Toutanji and Saafi $[67,68]$ then introduced a new hybrid column system for 
new construction consisting of concrete filled PVC tubes reinforced with external discrete FRP hoops at different spacings. In such a hybrid system, PVC serves as the cast-in-place formwork while the FRPPVC tube provides additional confinement to the core concrete. Moreover, a few research studies on concrete filled PVC tubes were undertaken $[62,70,71,76,77]$. However, experimental studies on CFT columns consisting of PVC tubes are limited to uniaxial compression tests [70]. The study by Gupta and Verma [76] on RC filled PVC tubes subjected to harsh environmental condition indicated that "no degradation in the strength and ductility of RC-filled poly-vinyl chloride tubular specimens was observed after submergence in sea water". Test results on RC filled PVC tubes submerged in saturated sea water (concentration 20 times higher than natural sea water) for 6 months revealed that the microstructure and chemical composition of the PVC jacket remained nearly identical after exposure to sea water (i.e., chemical action of sodium chloride and magnesium sulfate) [76]. It was then concluded that PVC tubes provide a safety jacket to their encased concrete core with improved strength and ductility. Most recently, Jian et al. [78] studied the performance of slender concrete-filled carbon FRP-PVC tubular (CFCT) columns of various slenderness ratios under uniaxial compression. However, only four CFCT specimens with discrete carbon FRP strips were tested. Moreover, there is a wealth of contradictory published data on PVC, "a kind of elastic material" [78] or a ductile plastic material [62, 70, 71]. For instance, the ductile failure of a PVC tube was observed up to a complete collapse of the plastic tube $[62,70,71,76]$. On the other hand, bursting (fracture) of the plastic tube toward the end the loading process was demonstrated with CFPT [77].

The main advantage of a CFST system is full concrete section confinement by the steel tube that is in turn constrained by the concrete and delayed from buckling. This composite action results in enhanced stiffness, strength, ductility and overall stability of the CFST system. However, due to high modulus of elasticity, the steel tube is subjected to a large portion of the axial load capacity and can still be buckled. On the contrary, the modulus of elasticity for PVC tubes is approximately $1 / 50$ of that of 
steel. The axial load carried by the PVC tube is substantially less than that by a steel tube of same size, which makes the PVC tube experience smaller premature buckling load due to its lower modulus.

Harries and Carey [79] were among the first researcher who investigated the effect of unbonded FRP wrap on the performance of FRP-confined concrete cylinders by introducing an approximately 0.08 mm thick plastic wrap used in kitchen between the FRP wrap and concrete cylinder. Their tests clearly indicated a reduction in the maximum obtainable confined concrete strength due to the use of the plastic wrap. Later, Xiao et al. [37] further evaluated the application of foam between the FRP wrap and steel tube in FRP-confined concrete-filled steel tubes.

In this study, a new composite confinement system with a FRP wrap outside a PVC tube with an energy dissipation medium in between is investigated. The energy dissipation medium is a thin, compressible, rubber-based foam that is designed to (1) regulate the change in confinement provided by the FRP wrap so that significant axial deformation of the confined cylinder without strength enhancement can be achieved prior to FRP rupture, and (2) dissipate impact energy generated by the FRP rupture so that the PVC tube is not fractured under slowly increased confinement. The FRP-confined concrete filled PVC tubular (CCFPT) cylinder with an energy dissipation medium could be advantageous over others when the brittle failure of FRP materials is not desirable for RC structures in high seismicity regions. Therefore, the compressive behavior of CCFPT cylinders is characterized under monotonically increasing axial loads in compression and compared with those of the concrete filled PVC tube (CFPT) and FRPwrapped (FW) specimens. The key parameters to be examined include the type and thickness of FRP wrap, the presence and thickness of compressible foam, and compressive loading area. To this endeavor, 17 CCFPT, 5 CFPT, and 14 FW cylinders with $152 \mathrm{~mm}$ in diameter and $305 \mathrm{~mm}$ in height were cast with normal strength concrete. The ultimate strength and strain as well as the stress-strain relationships are investigated and discussed. The potential of predicting the compressive behavior of CCFPT cylinders with seven existing stress-strain models developed for FRP-confined cylinders is assessed. 


\section{Experimental program}

\subsection{Details of cylinder specimens}

All the CCFPT, CFPT, and FW specimens were fabricated, cured and tested in the Structural Engineering High-Bay Research Laboratory (SERL) at Missouri University of Science and Technology. The cast specimens and the quality control/quality assurance/reference cylinders according to ASTM C39-12 [80] and C496-11 [81] and flexural beam specimens according to ASTM C78-10 [82] were covered with wet burlap and plastic wraps.

For each CFPT specimen, a Grey Schedule 40 PVC pipe was cut to the required length (i.e., 305 $\mathrm{mm}$ ) and then affixed at one end to a wood board as illustrated in Fig. 1(a), which functioned as a stay-inplace formwork during concrete casting. A FRP wrap was applied using a manual wet layup process, which required wrapping of an epoxy-resin impregnated fiber sheet around a PVC tube for each CCFPT specimen or around a precast concrete cylinder for each FW specimen. As illustrated in Fig. 1(b), the two ends of each specimen were then ground using a surface-grinding machine to remove irregularities, unevenness, and soft concrete and ensure that the specimen ends were orthogonal to its longitudinal axis. To avoid direct axial load transfer from loading platens, the FRP wrap was recessed by $5 \mathrm{~mm}$ at both ends of each CCFPT or FW specimen. The confinement materials for all specimens are summarized in Table 1.

The cylinder specimens under axial compressive loading were identified according to the confinement material (i.e., FRP, PVC, or FRP+PVC), where the FRP type, number of FRP layers, and PVC tube type are specified. Confinement tube is designated as either FW (i.e., FRP-wrapped), CFPT (i.e., concrete filled PVC tube), or CCFPT (i.e., confined concrete filled PVC tube). The symbols G, and C are used to represent the type of FRP-confinement, namely: carbon (C), or glass (G) preceded by the number of layers. For CFPT and CCFPT specimens the letter G was used in specimen designation to specify the PVC pipe schedule/color followed by a number that determines the PVC pipe schedule (ASTMD1785 [83] standard pressure rating). As stated earlier, the gray Schedule 40 PVC pipe was used for manufacturing all the CFPT, and CCFPT specimens in this study, hence the G40 designation was used 
accordingly. A final number was provided to identify between nominally identical specimens. Details on all the compressive specimens according to their type of confinement are presented later in Table 6. For example, a FRP-wrapped specimen confined with one layer of carbon FRP, which is the first in its group would be labelled as FW-1C\#1. Similarly, a CFPT specimen encased by the gray Schedule 40 PVC tube, and is third in its group would be labelled as CFPT-G40\#3. Lastly, a CCFPT specimen encased by the gray Schedule 40 PVC tube and one layer of carbon FRP, and is the first in its group would be labelled as CCFPT-G40-1C\#1.

As stated earlier, two companion CFPT specimens with 12-mm gap at both ends (i.e., CFPT-G40w gap\#1 and 2) were tested (see Fig. 2(d)). This gap was provided at both ends of the specimen to avoid compressive axial load resisted by the PVC tube. These specimens were tested to compare the relative performance of the CFPT system when either the entire cross section (i.e., PVC tube and concrete infill) or the infill concrete only is loaded.

Moreover, four CCFPT specimens including a foam layer between the PVC tube and FRP wrap as shown in Fig. 2(e) were added into the test matrix, and designated as CCFPT-G40-1G-foam\#1, 2, 3 and 4 specimens, respectively. Effect of the thickness of the foam layer on the axial stress-axial strain relationship of CCFPT specimens were studied by comparing the performance of two different thicknesses of the foam layer. For CCFPT-G40-1G\#1 and 2 specimens, a 4.175-mm foam layer was utilized. For CCFPT-G40-1G\#3 and 4 specimens, a 1-mm foam layer was affixed on the PVC tube prior to the FRP wrap application. All the four specimens were identical in terms to the encased concrete, PVC tube, and FRP wrap properties, except the thickness of the foam layer varied. 


\subsection{Material properties}

\subsubsection{Concrete}

A normal strength concrete mix with a target unconfined compressive strength $\left(f^{\prime}{ }_{c o}\right)$ of $50 \mathrm{MPa}$ at 28 days was used in the fabrication of cylinder specimens. The concrete mix was delivered by a local ready-mix concrete supplier (Rolla, MO). It consisted of ASTM Type I Portland cement as binder, crushed limestone with a maximum nominal aggregate size of $25 \mathrm{~mm}$ from the Potosi quarry (Potosi, MO), and river sands (Jefferson City plant, MO). Quality control/quality assurance (QC/QA) companion cylinders (ASTM:C39 [80] and ASTM:C496 [81]) and beams (ASTM:C78 [82]) were also cast from the mix. Table 2 presents fresh and hardened concrete properties of the mix in the present study. Plain concrete cylinders with 152 by $305 \mathrm{~mm}$ dimensions were tested at selected time intervals to determine the in-place unconfined concrete strength, $f^{\prime}{ }_{c o}$. The average compressive strength of axially loaded specimens throughout the period of testing was $49.5 \mathrm{MPa}$.

\subsubsection{FRP}

Table 3 compares the manufacturer-specified with measured properties of carbon and E-Glass fibers used in the preparation of cylinder specimens. The measured data was based on flat coupon tests (ASTMD3039 [84]). At least five tensile tests were conducted for each type of FRP fabrics instrumented with two electrical strain gages (one parallel and one perpendicular to the fibers direction), in addition to a clip-on extensometer. For each CCFPT or FW specimen, the PVC tube or concrete cylinder was first brushed with a thin layer of epoxy resin and then manually wrapped with an epoxy impregnated FRP sheet in the hoop direction. For CCFPT and FW specimens, the FRP sheet was overlapped with $152 \mathrm{~mm}$ and $144 \mathrm{~mm}$, respectively, to prevent premature debonding failure. 


\subsubsection{PVC}

Commercially available Grey schedule 40 PVC pipes (as per ASTM D1785 [83]) used for water supply with a nominal pressure of 1.24 MPa were used to prepare CFPT and CCFPT specimens. The selected PVC pipe as shown in Fig. 2 had grey color with an inside diameter (ID) of $152 \mathrm{~mm}$ and a minimum wall thickness of $7.11 \mathrm{~mm}$. All the CFPT, CCFPT, and FW specimens had a concrete core of $152 \mathrm{~mm}$ in diameter and $305 \mathrm{~mm}$ in height as shown in Table 1. Details of the CFPT, CCFPT, and FW specimens are illustrated in Fig. 2.

Mechanical properties of the PVC pipes were obtained by testing a minimum of five tensile dogbone coupon specimens (as per ASTM D638 [85]) as reported in Table 4. Each tensile PVC coupon specimen was instrumented with two electrical strain gages in axial and transversal directions, and a clipon extensometer to determine the modulus of elasticity and Poisson's ratio. Fig. 3(a) depicts the typical tensile stress-strain behavior of the PVC material. The PVC coupon specimens exhibited significantly ductile behavior reaching to an average fracture strain of $46 \%$ (i.e., $2 \sim 3$ times that of mild structural steel). The typical failure of PVC pipe tensile coupon specimens is illustrated in Fig. 4, where significant plastic elongation is evident. As shown in Fig. 3(a), the tensile behavior of PVC materials under tension can be divided into four regions: 1) linear-elastic; 2) onset of yielding and nonlinear up to the ultimate strength; 3) post-peak strain-softening; and 4) yielding plateau with $80 \%$ of the ultimate strength till fracture. PVC materials exhibited a substantially lower strength but higher ductility than FRP materials. The ductile behavior was observed from discoloration and white patches due to the flow of resin in Fig. 4 with stable post-peak residual strength up to a large fracture strain.

To evaluate the compressive property of PVC tubes used in CFPT and CCFPT specimens, two hollow PVC tube specimens were axially loaded in compression. They failed due to local elephant foot buckling and global buckling as illustrated in Fig. 5. The axial stress-strain relationships of the hollow PVC tubes under axial compression are illustrated in Fig. 3(c). The material properties of PVC tubes 
obtained from the axial compression tests are given in Table 5. By comparing Table 5 with Table 4, the measured mechanical properties (yield stress and ultimate strength) of PVC pipes under tension and compression differ by less than $1 \%$.

\subsection{Instrumentation and testing procedure}

For each cylinder specimen, three vertical linear variable differential transformers (LVDTs) were evenly distributed around the cylinder perimeter to measure axial deformation between the top and bottom sections of the specimen, as illustrated in Fig. 6(b). In addition, three horizontal LVDTs located at the mid-height of the cylinder were evenly distributed around the specimen to measure the lateral dilation (i.e., radial expansion) of the specimen under axial compressive loading. Moreover, PVC tube or FRP sheet of the specimen was instrumented at mid-height with three unidirectional strain gages to measure axial strains to correct the LVDT measurements at the early stage of loading. This is because the LVDT measurements at the early stage are often inaccurate due to potential slack in the test setup [86]. The hoop strain of a PVC tube or FRP sheet was also measured with three evenly-distributed unidirectional strain gages at mid-height outside the overlap region. For FW and CCFPT specimens, one additional hoop strain gage was installed on the overlap region of the FRP wrap. This strain gage was used to measure the potential discrepancy of hoop strain in the overlap region of the FW and CCFPT specimens. The average of the three strain measurements outside the overlap region is reported as the hoop strain of the specimen.

Axial load was applied on the composite cross section of concrete and PVC tube in some CFPT cylinder specimens as shown in Fig. 2(d). In this case, the PVC tube is in a biaxial stress state with the direct axial stress and the hoop stress due to concrete dilation. For comparison, the PVC tube in other CFPT specimens was reset to leave a 12-mm gap at both ends, making the PVC tube subjected to the uniaxial hoop stress only as seen in Fig. 2(d).

After 28 days of curing, specimens were tested in displacement control at approximately $0.5 \mathrm{~mm}$ per minute on a $2670-\mathrm{kN}$ capacity MTS testing machine in the Highbay Structures Laboratory. Prior to 
testing, both ends of the specimens were ground with a concrete end grinding machine to ensure a uniform distribution of the applied axial load. For each CFPT and CCFPT specimen, the load was applied to its entire cross section (i.e., PVC tube and concrete). A data acquisition system was utilized to record the load, displacement, and strain of specimens throughout each test. The unconfined concrete compressive strength $\left(f^{\prime}{ }_{c o}\right)$ was determined at the time of testing, and its corresponding axial strain $\left(\varepsilon_{c o}\right)$ was calculated according to Tasdemir et al. [87] as follows:

$$
\varepsilon_{c o}=\left(-0.067 f_{c o}^{\prime}+29.9 f_{c o}^{\prime}+1053\right) \times 10^{-6}
$$

where $f^{\prime}{ }_{c o}$ is in MPa. This relation was only used for the unconfined reference specimens.

\section{Test results}

\subsection{Failure modes}

The test results of all specimens are summarized in Table 6. The typical failure modes observed during tests are illustrated in Fig. 7 for various types of confinement materials.

The FW specimens and the CCFPT specimens without a thin layer of foam exhibited a brittle rupture of FRP wraps either over the entire height, as shown in Figs. 7(a, b, g, and h), or around the midheight, as shown in Figs. 7(c, d, i and j). The rupture of FRP wraps in the specimens immediately resulted in catastrophic failure of the core concrete due to loss of confinement. The CFPT specimens exhibited a very ductile behavior with gradual post-peak strength degradation and experienced no cracking or PVC fracture as the core concrete continued to dilate and push the PVC wall outwards to bulge and deform significantly as shown in Fig. 7(e). Due to non-uniform dilation of the core concrete, the highly stressed region of the PVC tube showed discoloration or white patch due to the flow of resin, as shown in Fig 7(f). For the CFPT specimens with or without gap, the core concrete was thoroughly crushed and somewhat pulverized and the PVC tube remained intact. The typical shear cone formation for the CFPT-G40-w gap\#1 in Fig. 7(f) can be observed due to discoloration of the highly stressed region on the PVC tube. The 
FW and CCFPT specimens exhibited similar shear cone type failure to a less degree depending on the ultimate dilation of the confining jacket.

Further examination on the CCFPT specimens without a thin layer of foam indicated that the PVC tube immediately fractured upon FRP rupture due to sudden transfer of the confining pressure from the FRP sheet to the PVC tube, regardless of the type and number of FRP layers. The PVC tube was not able to absorb a large amount of surge energy released from the rupture of FRP sheet. Indeed, the rupture of CCFPT specimens was more explosive than that of FW specimen as a louder sound was heard during tests of the CCFPT specimens. As a result, the core concrete in the CCFPT specimens was damaged more severely than that of the FW specimens. This phenomenon was due to the higher confinement pressure developed in the FRP wrap of the CCFPT specimens compared to the FW companion specimens, which resulted in obtainment of higher ultimate stress and strain values for the CCFPTs, as discussed later in the paper on the influence of confinement type.

However, the CCFPT specimens with a thin layer of foam between the FRP sheet and PVC tube demonstrated a ductile behavior similar to their CFPT counterparts with no FRP wrap. In this case, the FRP rupture in each CCFPT specimen was gradual since the progressive fracture of fibers caused tearing and splintering of the FRP sheet along the specimen's height as shown in Figs. 7(k, l). The observed behavior was similar to the failure mode of confined concrete filled FRP tubes with inclined fibers (i.e., 45 and 60 degrees) reported by Vincent and Ozbakkaloglu [86]. Contrary to the local rupture of FRP wrap in the CCFPT with no foam, introduction of the foam in a CCFPT specimen resulted in a more-like distributed rupture of the FRP wrap. In this case, the PVC tube remained intact upon FRP rupture; no catastrophic failure occurred.

\subsection{Stress-strain behavior and ultimate condition}

The ultimate axial strength $\left(f^{\prime}{ }_{c u}\right)$ recorded at the failure of a specimen and its corresponding axial strain $\left(\varepsilon_{c u}\right)$ as well as the FRP hoop rupture strain $\left(\varepsilon_{h, \text { rup }}\right)$ of each confined specimen are reported in Table 
6; the axial stress-strain relationships are presented in Fig. 8. The ultimate strength $\left(f_{c u}^{\prime}\right)$ and the peak stress $\left(f^{\prime}{ }_{c c}\right)$ are presented in Table 6 according to the type of stress-strain relationships. For stress-strain relationship that consisted of a descending post-peak branch, the ultimate strength $\left(f^{\prime}{ }_{c u}\right)$ was lower than the recorded peak stress $\left(f^{\prime}{ }_{c c}\right)$; both the ultimate strength $\left(f^{\prime}{ }_{c u}\right)$ and the peak stress $\left(f^{\prime}{ }_{c c}\right)$ are reported. For stress-strain relationship with a monotonically increasing second branch, the ultimate strength $\left(f_{c u}^{\prime}\right)$ and peak stress $\left(f^{\prime}{ }_{c c}\right)$ were equal; only $f_{c c}^{\prime}$ is reported in Table 6. To establish the axial stress-strain relationships of all CFPT and CCFPT specimens except CFPT-G40-w gap\#1, 2, the applied load on the confined concrete for a given axial strain was determined by subtracting the axial load resisted by the PVC tube from the total load applied. The axial load resisted by the PVC tube was determined based on the results of hollow PVC tube compression tests, assuming that the load-strain behavior of PVC tubes used in a CFPT or CCFPT specimen is equal to that of the corresponding hollow PVC tube.

The ultimate condition (i.e., $f_{c u}^{\prime}, \varepsilon_{c u}$ and $\varepsilon_{h, \text { rup }}$ ) of FW and CCFPT specimens without any foam was quite clear due distinct rupture of the FRP wrap observed during testing. However, for CFPT specimens and the CCFPT specimens with a thin layer of foam (CCFPT-G40-1G-foam\#1, 2, 3 and 4), no catastrophic failure was observed; tests were terminated after excessive compression (i.e. 7\%). As shown in Table 6, the ultimate conditions (i.e., $f_{c u}^{\prime}, \varepsilon_{c u}$ and $\varepsilon_{h, \text { rup }}$ ) for these specimens corresponded to $20 \%$ drop below the recorded peak stress (i.e., threshold of $0.8 f^{\prime}{ }_{c c}$ ). This threshold has been widely adopted in similar studies (e.g., [86]); it was used herein for the sake of consistency since the method used in determining the ultimate condition may significantly influence the ultimate strain. With such a threshold, all CFPT specimens with gap have a relatively small strain enhancement ratio $\left(\varepsilon_{c u} / \varepsilon_{c o}\right)$ since they still demonstrate a stable load-carrying capacity upon $40 \%$ drop from the measured peak stress as shown in Fig. 8(f).

The ultimate hoop rupture strain $\left(\varepsilon_{h, \text { rup }}\right)$ of each specimen obtained from the average of three lateral strain gages installed outside the overlapping FRP region is tabulated in Table 6. Past studies have indicated that the hoop rupture strains obtained from FRP-confined concrete specimens and double skin 
tubular columns are usually smaller than the ultimate tensile strain $\left(\varepsilon_{f u}\right)$ of component fibers as advertised by manufacturers $[4,5,14,55,88-91]$. Different reasons causing this phenomena have been cited in the literature, including: (1) cracking of the confined concrete results in non-uniform strain distribution and stress concentration on the FRP wrap, (2) curvature of the FRP reduces its strain capacity, (3) geometric imperfection of the column, (4) non-uniform bonding of the FRP to the column, (5) misalignment of fibers, and (6) geometric discontinuity within the FRP overlap [3, 5, 90]. This apparent in-situ FRP jacket inefficiency could result in low confining pressure. The strain reduction factor $\left(k_{\varepsilon}\right)$ reported in Table 6 is calculated for FW and CCFPT specimens by:

$$
k_{\varepsilon}=\frac{\varepsilon_{h, r u p}}{\varepsilon_{f u}}
$$

Note that the strain reduction factor $\left(k_{\varepsilon}\right)$ presented for the CCFPT specimen with a thin layer of foam (i.e., CCFPT-G40-1G-foam\#1, 2, 3 and 4) in Table 6 is approximate only since there was no distinct hoop rupture of FRP definable in these specimens.

\section{Analysis of test results}

\subsection{Stress-strain behavior}

When concrete is confined by an enclosing material (e.g., FRP sheet or PVC tube) and subjected to monotonically increasing axial compression, passive confining pressure is developed in the jacket as the enclosed concrete tends to dilate laterally due to Poisson's effect, resulting in a multiaxial state of stress. The hoop stress in the confining jacket increases as the internal pressure develops between the jacket and the confined concrete. Hence, confinement action depends on two main factors: 1) radial stiffness of the confining jacket restraining the concrete from being dilated; and 2) lateral dilation of the concrete under axial compression. Depending on the type of confinement materials, distinct stress-strain relationships were obtained as shown in Fig. 8. Specifically, the axial behavior of confined specimens 

specimens and the CCFPT specimens with no foam exhibited a monotonically ascending strain-hardening response up to FRP's rupture as shown in Figs. 8(b, d, h and k). It can also be observed in Figs. 8(h, k) that some of the CCFPT specimens experienced a small drop in strength after the transition point between the initial ascending branch and the following branch. The gradual softening can be attributed to uneven micro-cracking of the encased concrete and local deformation of the PVC tube. However, when adequate confinement by FRP is provided (i.e., CCFPT-G40-3C\#1, 2 and 3 and CCFPT-G40-3G\#1, 2 and 3), the CCFPT specimens exhibited a monotonically ascending axial stress-strain response in the second branch. Therefore, the post-peak stress-strain relationship of the CCFPT specimens is influenced by stiffness of the confining jacket. A similar conclusion was drawn for FRP-confined columns (e.g., [5, 91]).

For lightly confined tested FW and CCFPT specimens (i.e., with 1-ply of FRP), the strength enhancement ratio $\left(f^{\prime}{ }_{c c} / f^{\prime}{ }_{c o}\right)$ and strain enhancement ratio $\left(\varepsilon_{c u} / \varepsilon_{c o}\right)$ were significantly smaller than those of their companion ones with adequate confinement (i.e., with 3-plies of FRP) as reported in Table 6. 
However, the strain enhancement ratio was more pronounced in case of GFRP wraps compared to CFRP fabrics.

The CFPT specimens with gaps at both ends (CFPT-G40-w gap\#1 and 2) demonstrated a prepeak behavior similar to their companion specimens with no gap. Around the peak stress, the unconfined concrete outside the PVC tube started to crush, resulting in rapid post-peak strength degradation on the axial stress-strain relationship as shown in Fig. 8(f). However, the PVC tube in this series of specimens still demonstrated a very ductile behavior, similar to CFPT specimens with full height tube. The shear type failure and the direction of a shear crack associated with the discolored region on the PVC tube is highlighted in Fig. 7(f). The presence of the PVC tube, even when it partially confined the concrete core in the middle portion, allowed the obtainment of excessive axial strain.

The CCFPT specimens with a thin layer of foam exhibited a distinct axial stress-strain relationship due to the cushioning property or space provided by the foam layer between the PVC tube and FRP wrap. All the four specimens demonstrated consistent behavior up to the peak stress with a smooth, gradual post-peak strength reduction as marked in Fig. 8(j). The post-peak strength reduction was completely stable since the space occupied by and the flexibility of the foam regulated the confinement pressure, reducing or eliminating impact effect on the PVC tube and thus preventing the PVC tube from sudden fracture. The effect of the foam thickness becomes significant on the second region of the postpeak axial stress-strain relationship (i.e., plateaued region on the axial stress-strain relationship after the drop of post-peak strength). The thicker the foam in specimens (i.e., CCFPT-G40-1G-foam\#1 and 2 with 4.175-mm foam versus CCFPT-G40-1G-foam\#3 and 4 with 1-mm foam), the larger the strength drop would be obtained before the GFRP wrap starts to provide the confining pressure. The greater strength reduction for the specimens with thicker foam is due to the larger gap provided by the foam layer, allowing larger dilation of the core concrete before the FRP wrap becomes completely engaged. In other words, the FRP wrap becomes engaged at a larger level of axial strain and the CCFPT cylinder hence experienced a larger strength loss. Therefore, different ultimate axial strains can be obtained by changing 
the foam layer thicknesses. Moreover, presence of the foam layer delayed the onset of GFRP rupture as marked in Fig. 8(j), compared to the CCFPT specimens without foam. As a result, the specimens with foam are very ductile with gradual rupture of the GFRP.

In summary, a sudden rupture of the entire GFRP wrap in specimens without a foam layer resulted in immediate fracture of the PVC tube. However, the GFRP wrap in specimens without a foam layer exhibited a progressive rupture that did not lead to immediate fracture of the PVC tube due to the space or the impact absorption provided by the foam. In essence, the presence of the foam layer (i.e., CCFPT-G40-1G-foam\#1, 2, 3 and 4) altered the failure mode of CCFPT specimens from brittle to ductile failure, as shown in Fig. 7(k, 1).

\subsection{Influence of confinement pressure and detail}

As expected, increase in the number of FRP layers in the FW and CCFPT specimens led to an increase of ultimate conditions (i.e., $f_{c u}^{\prime}$ and $\varepsilon_{c u}$ ) as seen in Table 6, and improved the strength enhancement ratio $\left(f^{\prime}{ }_{c u} / f^{\prime}{ }_{c}\right)$ and strain enhancement ratio $\left(\varepsilon_{c u} / \varepsilon_{c o}\right)$. Figs. $9(\mathrm{a}, \mathrm{b})$ illustrate the influence of lateral confinement pressure $\left(f_{l u}\right)$ provided by different number of FRP layers on the axial stress-strain relationships of the FW and CCFPT specimens, respectively. In preparation of the FW and CCFPT specimens, the number of FRP layers was determined to provide a comparable nominal confinement ratio $\left(f_{l u} / f^{\prime}{ }_{c o}\right)$ between the FW and CCFPT specimens so that a meaningful comparison can be made between the two types of specimens. The nominal confinement ratio $\left(f_{l l} / f^{\prime}{ }_{c o}\right)$ represents the lateral confinement pressure $\left(f_{l u}\right)$ divided by the in-place unconfined concrete strength $\left(f^{\prime}{ }_{c o}\right)$. When a uniform confinement pressure is assumed around a circular cross section, it can be calculated by [5, 14, 86, 92]:

$$
\frac{f_{l u}}{f_{c o}^{\prime}}=\frac{2 t_{f} f_{f u}}{D f_{c o}^{\prime}}=\frac{2 t_{f} E_{f} \varepsilon_{f u}}{D f_{c o}^{\prime}}
$$

where $t_{f}=$ total nominal thickness; $E_{f}=$ the modulus of elasticity; $\varepsilon_{f u}=$ the ultimate tensile strain of fibers; and $D=$ the diameter of confined concrete. However, as mentioned earlier and reported in Table 6 , the 
FRP hoop rupture strain $\left(\varepsilon_{h, \text { rup }}\right)$ is often lower than that of the ultimate tensile strain of fibers $\left(\varepsilon_{f u}\right)$ obtained from flat coupon tests and/or reported by manufacturers. Therefore, a strain reduction factor, $k_{\varepsilon}$, was introduced; the actual confinement ratio $\left(f_{l u, d} d f^{\prime}{ }_{c o}\right)$ was calculated and presented in Table 6 by:

$$
\frac{f_{l u, a}}{f_{c o}^{\prime}}=\frac{2 t_{f} f_{f u} k_{\varepsilon}}{D f_{c o}^{\prime}}=\frac{2 t_{f} E_{f}\left(\varepsilon_{f u} k_{\varepsilon}\right)}{D f_{c o}^{\prime}}=\frac{2 t_{f} E_{f} \varepsilon_{h, r u p}}{D f_{c o}^{\prime}}
$$

The nominal confinement ratio $\left(f_{l u} / f^{\prime}{ }_{c o}\right)_{P V C}$ of a PVC tube can be calculated in a similar way:

$$
\left(\frac{f_{l u}}{f_{c o}^{\prime}}\right)_{P V C}=\frac{2 t_{P V C} f_{y, P V C}}{D_{\text {int }} f_{c o}^{\prime}}
$$

where $t_{P V C}=$ thickness; $f_{y, P V C}=$ yield strength; $D_{\text {int }}=$ inside diameter of the PVC tube. For $f_{l u}=3.8 \mathrm{MPa}$, the nominal confining ratio of a Grey Schedule 40 PVC tube used in this study was determined to be approximately 0.08 as presented in Table 6. This level of confinement pressure is very small and approximately half of the confinement pressure provided by 1 ply of CFRP or GFRP.

Figs. 9(a, b) show the representative axial stress-strain relationships of tested FW and CCFPT specimens with various actual confinement ratios $\left(f_{l u, d} / f^{\prime}{ }_{c o}\right)$. The actual confinement ratios $\left(f_{l u, d} / f^{\prime}{ }_{c o}\right)$ with 1- and 3-plies of FRP are approximately equal to 0.12 and 0.37 , respectively, regardless of the type of FRP (both CFRP and GFRP). Depending on the level of lateral confining pressure, either a descending or monotonically ascending first-post-peak behavior can be observed in Fig. 9. Although similar in shape of the axial stress-strain relationship, the ultimate conditions (i.e., $f_{c u}{ }_{c u}$ and $\varepsilon_{c u}$ ) were affected by the type of FRP particularly when the number of FRP plies increases as shown in Table 6. This is because the ultimate rupture strain of fibers $\left(\varepsilon_{f u}\right)$ is strongly related with the attainable ultimate axial strain of the FW and CCFPT specimens as demonstrated for FRP-confined concrete $[89,93]$. For example, the FW and CCFPT specimens with 3-plies of GFRP (FW-3G\#2 in Fig. 9(a) and CCFPT-G40-3G\#2 in Fig. 9(b)) experienced greater strength enhancement ratio $\left(f^{\prime}{ }_{c c} / f^{\prime}{ }_{c o}\right)$ and strain enhancement ratio $\left(\varepsilon_{c u} / \varepsilon_{c o}\right)$ than those specimens with 3-plies of CFRP (FW-3C\#2 in Fig. 9(a) and CCFPT-G40-3C\#2 in Fig. 9(b)). As 
presented in Table 6, the FW and CCFPT specimens with GFRP had a significant increase of strain capacity $\left(\varepsilon_{c u}\right)$ and a moderate increase of peak stress $\left(f^{\prime}{ }_{c c}\right)$ than those with CFRP. Although the CCFPT specimens with 3-plies of FRP as presented in Figs. 8(h, k) exhibited a slight strength loss right after the initial peak, the strength loss is temporary and the ultimate strength and strain were improved significantly in comparison with specimens with 1-ply of FRP as shown in Figs. 8(g, i).

Fig. 10(a) compares the axial stress-strain relationships of CFPT specimens without and with gap at both ends. The presence of gap does not affect the linear ascending region up to the peak stress but does change the post-peak response. While the CFPT-G40\#1 specimen without gap shows continuous strength degradation due to gradual plastification of the PVC tube, the CFPT-G40-w gap\#1 (with gap) demonstrates a rapid and unstable strength loss due to local crushing of the unconfined concrete in the gap region. After significant crushing of the unconfined concrete in CFPT-G40-w gap\#1 specimen (similar in CFPT-G40-w gap\#2), the specimen recovered to undergo further axial deformation and the plastic plateau region, similar to CFPT-G40\#1 specimen. Comparison of CFPT-G40\#1 and CFPT-G40-w gap\#1 specimens also allows an understanding of the axial load resisted by the PVC tube in CFPT specimens. While the entire composite cross section of CFPT-G40\#1 specimen was axially loaded, only the core concrete of CFPT-G40-w gap\#1 was loaded. However, the two specimens had an approximate peak stress of $50 \mathrm{MPa}$, which represents the in-place unconfined concrete strength $\left(f^{\prime}{ }_{c o}\right)$. Fig. 10(a) and the strength enhancement ratio $\left(f^{\prime}{ }_{c o} / f^{\prime}{ }_{c o}\right)$ reported in Table 6 for CFPT specimens (CFPT-G40\#1, 2 and 3) and CFPT specimens with gap (CFPT-G40-w gap\#1 and 2) clearly indicate that the axial load resisted by the PVC tube is negligible.

Fig. 10(b) compares the axial stress-strain relationships of CCFPT specimens with and without a foam layer between the PVC tube and the FRP wrap. The CCFPT specimens with a foam layer (CCFPTG40-1G-foam\#1 and 3) had more significant post-peak strength drop and ultimate strain $\left(\varepsilon_{c u}\right)$ enhancement than those of CCFPT specimen without a foam layer (CCFPT-G40-1G\#2). The foam layer reduced the strain demand on the GFRP wrap which resulted in slower development of confining pressure 
and thus higher ultimate axial strain. In addition to the improvement in mechanical property, the foam between the PVC tube and FRP wrap can also reduce the impact susceptibility of CCFPT columns under impact loading [94], which is beyond the scope of current study. The presence of foam indicates a reduction of strength enhancement ratio $\left(f^{\prime}{ }_{c c} / f^{\prime}{ }_{c o}\right)$ of CCFPT specimens. The effect of foam thickness can also be observed in Fig. 10(b). The increase in foam thickness (CCFPT-G40-1G-foam\#1) results in a greater post-peak strength loss and larger ultimate axial strain.

\subsection{Influence of confinement type}

Fig. 11 compares the representative axial stress-strain relationships of specimens with various confinement details (i.e., PVC in CFPT, FRP+PVC in CCFPT, and FRP in FW). The CFPT specimen demonstrates a similar behavior to the unconfined concrete up to peak stress but is followed by a strength plateau region. In comparison with CFPT specimens, the adequately confined CCFPT specimens demonstrate a bilinear response similar to its companion FW specimens. However, it can be seen from Fig. 11 and Table 6 that CCFPT specimens often developed higher ultimate axial stresses $\left(f^{\prime}{ }_{c u}\right)$ and ultimate axial strains $\left(\varepsilon_{c u}\right)$ than those of FW specimens with the same number of FRP layers. This is attributed to the additional confinement on the core concrete by the PVC tube. Although the PVC tube provided relatively low confinement, it provides a mechanism to uniformly distribute the stress induced by concrete dilation and thus reduces the stress concentration due to uneven concrete cracking on the FRP wrap. The rupture of the FRP wrap is thus governed by the overall dilation behavior of the PVC tube, which results in obtainment of larger hoop rupture strains (i.e., larger $k_{\varepsilon}$ ). A similar observation on the influence of the effect of stress concentration on FRP jacket has been previously reported in the literature (e.g., [95]). Table 6 indicates that the CCFPT specimens consistently exhibited larger strain reduction factors $\left(k_{\varepsilon}\right)$ than the FW wrapped specimens. Hence, considerably higher strain enhancement ratios were observed for the CCFPT specimens, which corresponds to higher confinement pressure (i.e., higher energy) developed in CCFPTs compared to FWs prior to ultimate failure. Subsequently, larger amount of energy would be released upon FRP rupture in case of CCFPTs without foam compared to FWs. Hence, 
as stated earlier louder sound and more severe damage to the core concrete was observed in the CCFPTs without foam, compared to the companion FW configuration.

The average hoop strain reduction factors $\left(k_{\varepsilon}\right)$ and corresponding standard deviations $(S D)$ from the FW specimens and CCFPT specimens without a foam layer are presented in Table 7 for each type of confinement material. As stated earlier, no distinct hoop rupture of FRP wraps was observed for these specimens. The obtained results indicate that the confinement type affects the mean $k_{\varepsilon}$ with an average value of 0.744 and 0.839 for the FW and CCFPT specimens, respectively. The $k_{\varepsilon}$ comparison indicates that the FRP wrap in the CCFPT composite system is more efficient than that in the FW specimen. Table 7 also indicates that, while the mean $k_{\varepsilon}$ values for the CFRP $\left(k_{\varepsilon}=0.715\right)$ and GFRP $\left(k_{\varepsilon}=0.781\right)$ wrap in the FW specimens are close, those for the CFRP $\left(k_{\varepsilon}=0.785\right)$ and GFRP $\left(k_{\varepsilon}=0.903\right)$ in the CCFPT configuration are quite different.

Lim and Ozbakkaloglu [96] recently proposed a strain reduction factor $\left(k_{\varepsilon}\right)$ equation for FRPconfined normal and high strength concrete $[4,96]$ as follows.

$$
k_{\varepsilon}=0.9-2.3 f_{c o}^{\prime} \times 10^{-3}-0.75 E_{f} \times 10^{-6}
$$

where $f_{c o}^{\prime}$ and $E_{f}$ are in MPa. This expression is applicable for FRP-confined concrete with an unconfined concrete strength up to $120 \mathrm{MPa}$ and a FRP's modulus of elasticity of $100,000 \mathrm{MPa} \leq E_{f} \leq$ 640,000 MPa which is confined by any of CFRP, GFRP, AFRP, high-modulus CFRP (HM CFRP), and ultra-high-modulus CFRP (UHM CFRP). GFRP-confined specimens with $E_{f}$ lower than $60,000 \mathrm{MPa}$ or $\varepsilon_{f}$ greater than $4.0 \%$ were excluded in the development of Eq. (6) [96]. For the tested specimens in this study, the obtained strain reduction factors $\left(k_{\varepsilon}\right)$ for the CFRP and GFRP from Eq. (6) would be 0.6 and 0.73 , respectively, which are not so far away from the measured mean value (0.79) for all the tested specimens. Therefore, Eq. (6) may be applied to determine the $k_{\varepsilon}$, for the tested CCFPT specimens since the soft PVC tube in CCFPT specimens contributes little to the axial load capacity; their ultimate strength 
is mainly due to the confinement provided by the FRP wrap. Consequently, the CCFPT specimens failed similarly to the FW specimens.

Fig. 12 plots the strength enhancement ratio $\left(f^{\prime}{ }_{c d} / f^{\prime}{ }_{c o}\right)$ and strain enhancement ratio $\left(\varepsilon_{c u} / \varepsilon_{c o}\right)$ as a function of actual confinement ratio $\left(f_{l u, d} / f^{\prime}{ }_{c o}\right)$ for various confinement types (i.e., FW, CFPT, and CCFPT). The obtained trend lines for strength and strain enhancement ratios for FW and CCFPT specimens indicate their similar behavior with a nearly identical trend line for strength enhancement ratio (Fig. 12(a)). However, the CCFPT specimens demonstrate greater improvement in strain enhancement ratio $\left(\varepsilon_{c u} / \varepsilon_{c o}\right)$ compared to companion $\mathrm{FW}$ specimens (Fig. 12(b)). It is also evident that the strength enhancement ratio for the CFPT is significantly smaller compared to the adequately confined FW, and CCFPT specimens, and relatively insignificant. However, noticeable improvement in strain enhancement ratio for the CFPT configuration is observed.

\section{Applicability of existing stress-strain models for CCFPT behavior prediction}

To appropriately design a CCFPT system, axial strength and strain enhancement ratios must be determined accurately. In this section, seven existing strength and strain models as presented in Table 8 are verified against the obtained experimental results from the FW and CCFPT specimens to understand their applicability for the proposed composite system. Six models [97-102] were chosen from over 80 models reviewed and reported by Ozbakkaloglu et al. [5]. The last model was selected from the most recent study by Ozbakkaloglu and Lim [4] in which a new design-oriented model was developed using 3042 test results from carefully chosen experimental tests through an extensive review of the literature. Since these models were developed to predict the ultimate conditions of FRP-confined concrete with a monotonically increasing axial stress-strain relationship (i.e., ascending behavior of second region), FW and CCFPT specimens that exhibited ascending post-peak behaviors were selected for this verification.

To measure the accuracy of various models, an average absolute error (ARE) is defined as follows: 
where $\bmod _{i}$ represents the model prediction, $\exp _{i}$ denotes the experimental value, and $N$ is the total number of datasets (tested specimens). The strength enhancement ratio $\left(f^{\prime}{ }_{c c} / f^{\prime}{ }_{c o}\right)$ and strain enhancement ratio $\left(\varepsilon_{c u} / \varepsilon_{c o}\right)$ were evaluated for FW specimens with adequate transverse confinement (i.e., 3 ply of FRP) and CCFPT specimens with no foam layer (CCFPT-G40-1G\#1, 2, and 3).

The predicted strength and strain enhancement ratios $\left(\left(f^{\prime}{ }_{c c} / f^{\prime}{ }_{c o}\right)_{\text {model }}\right.$ and $\left.\left(\varepsilon_{c u} / \varepsilon_{c o}\right)_{\text {model }}\right)$ are compared in Figs. 13 and 14 with the test results $\left(\left(f^{\prime}{ }_{c c} / f^{\prime}{ }_{c o}\right)_{\text {experimental }}\right.$ and $\left.\left(\varepsilon_{c u} / \varepsilon_{c o}\right)_{\text {experimental }}\right)$. Table 9 presents the AAE of strength and strain enhancement ratio predictions for FW and CCFPT specimens. For strength enhancement ratio prediction, all the studied models perform reasonably well for FW and CCFPT specimens with an AAE less than 15\%. The Wei and Wu [101] unified stress-strain model of FRPconfined concrete provided the most accurate strength prediction for both the FW and CCFPT test specimens. For strain enhancement ratio prediction, only Ozbakkologlu and Lim [4], Youssef et al. [102], and Lam and Teng [99] resulted in an AAE less than $15 \%$ for FW specimens. The model by Ozbakkologlu and Lim [4] is most accurate with an AAE of $6.97 \%$ for the FW specimens. The Shehata et al. [100] model is least accurate in strain enhancement ratio prediction for the FW specimens. The strain enhancement prediction accuracy for CCFPT specimens is overall less accurate than that for FW specimens. For example, Ozbakkologlu and Lim [4], Lam and Teng [99], and Youssef et al. [102] gave an AAE less than $30 \%$. The Ozbakkologlu and Lim [4] model is the most accurate in strain enhancement prediction for the CCFPT specimens. This particular model was developed as a unified strain enhancement relation based on an extensive number of carefully chosen FRP-confined concrete tests, wherein the axial strain $\left(\varepsilon_{c u}\right)$ is quantified as a non-linear function of the most affecting parameters on strain enhancement, namely, confinement jacket stiffness, hoop rupture strain $\left(\varepsilon_{h, \text { rup }}\right)$, and unconfined concrete strength $\left(f^{\prime}{ }_{c o}\right)$. Other models such as Benzaid et al. [97] and Bisby et al. [98] introduced a linear 
relationship between the strain enhancement and lateral confinement pressure, resulting in a relatively large deviation of model predictions compared to test results.

\section{Conclusions}

Based on visual observations, test results, and statistical analyses, the following conclusions can be drawn:

- The PVC tube in a CFPT cylinder added little to axial load capacity due to its low modulus of elasticity and yield strength. Even so, leaving a small PVC gap at two ends of the cylinder resulted in rapid post-peak strength degradation due to crushing of the unconfined concreate. The PVC tube also provided a relatively low confining pressure on the cylinder. But it can cope with significant concrete dilation and make the concrete cylinder ductile with a strain softening post-peak response. No fracture or crack was observed in PVC tubes tested.

- By introducing additional confinement, the FRP wrap on a CCFPT cylinder can effectively delay outward local buckling of the confined PVC tube and restrain the lateral dilation of the encased concrete, thus increasing both strength and strain capacities of the cylinder.

- The post-peak stress-strain behavior of a CCFPT cylinder proved to be significantly affected by the confining pressure from FRP wrap. When adequately confined by FRP, both carbon and glass FRP resulted in a monotonically increasing stress-strain behavior with an ascending second region. In comparison with carbon wraps, glass wrapping provided significantly greater strain enhancement for the CCFPT cylinder.

- The CCFPT cylinder exhibited a brittle, explosive-type failure with a sudden loss of axial load capacity since FRP rupture suddenly transferred substantial confining pressure to the PVC tube that fractured instantaneously. By introducing an impact energy absorption medium of compressible foam between the FRP wrapping and the PVC tube, the confined CFPT demonstrated highly ductile behavior similar to the regular CFPT. However, the post- 

and the PVC tube.

- The stress-strain curves of CCFPT specimens without compressible foam resembled those of FW specimens with slightly larger ultimate strength and significantly larger ultimate strain. Therefore, the energy dissipation ability of the CCFPT specimens is significantly higher than that of the FW specimens.

- The seven existing stress-strain models assessed can accurately predict the ultimate strength of axially-loaded CCFPT columns with an average absolute error of less than $15 \%$. The unified stress-strain model by Wei and $\mathrm{Wu}[101]$ provided the most accurate ultimate strength predictions for CCFPT and FW specimens. Unlike the ultimate strength, the ultimate strain was predicted with an average absolute error of as high as 67\%. The model by Ozbakkaloglu and Lim [4] gave the most accurate ultimate strain predictions for CCFPT and FW specimens with $26.3 \%$ and $6.97 \%$ error, respectively. Overall, the model by Lam and Teng [86] can reasonably predict both the ultimate strength and the ultimate strain of CCFPT specimens by $8.3 \%$ and $26.4 \%$, respectively.

Additional tests are required to further understand the mechanical behavior and durability properties of FRP-PVC-concrete composite columns under concentric and eccentric axial, and lateral flexural loading configurations. The types of FRP fabrics, the schedules of PVC pipes [83], pipe diameters, and different thicknesses of the foam layer between FRP wrap and the PVC tube should be investigated accordingly.

\section{Acknowledgments}

Financial support for this study was provided in part by the U.S. National Science Foundation under Award No. CMMI-1030399 and the Department of Civil, Architectural, and Environmental Engineering at Missouri University of Science and Technology. The views, opinions, findings, and conclusions reflected in this paper are those of the authors only and do not necessarily reflect the official 
O’Connor, Amir Ghazanfari, and Hassan Golpour for their assistance in concrete casting.

\section{References}

[1] Mander JB, Priestley MJ, Park R. Theoretical stress-strain model for confined concrete. Journal of structural engineering. 1988;114(8):1804-26.

[2] Nanni A, Bradford NM. FRP jacketed concrete under uniaxial compression. Construction and Building Materials. 1995;9(2):115-24.

[3] Teng J, Lam L. Behavior and modeling of fiber reinforced polymer-confined concrete. Journal of Structural Engineering. 2004;130(11):1713-23.

[4] Ozbakkaloglu T, Lim JC. Axial compressive behavior of FRP-confined concrete: Experimental test database and a new design-oriented model. Composites Part B: Engineering. 2013;55:607-34.

[5] Ozbakkaloglu T, Lim JC, Vincent T. FRP-confined concrete in circular sections: Review and assessment of stress-strain models. Eng Struct. 2013;49:1068-88.

[6] Nanni A, Norris M, Bradford N. Lateral confinement of concrete using FRP reinforcement. ACI Special Publication. 1993;138.

[7] Lopez A, Galati N, Alkhrdaji T, Nanni A. Strengthening of a reinforced concrete bridge with externally bonded steel reinforced polymer (SRP). Composites Part B: Engineering. 2007;38(4):429-36.

[8] Teng J, Chen J, Smith ST, Lam L. Behaviour and strength of FRP-strengthened RC structures: a stateof-the-art review. Proceedings of the ICE-Structures and Buildings. 2003;156(1):51-62.

[9] Fam AZ, Rizkalla SH. Confinement model for axially loaded concrete confined by circular fiberreinforced polymer tubes. ACI Structural Journal. 2001;98(4).

[10] Zaghi AE, Saiidi MS, Mirmiran A. Shake table response and analysis of a concrete-filled FRP tube bridge column. Composite Structures. 2012;94(5):1564-74.

[11] Vosooghi A, Saiidi MS. Design guidelines for rapid repair of earthquake-damaged circular RC bridge columns using CFRP. Journal of Bridge Engineering. 2012;18(9):827-36.

[12] Eslami A, Ronagh H. Effect of FRP wrapping in seismic performance of RC buildings with and without special detailing-A case study. Composites Part B: Engineering. 2013;45(1):1265-74.

[13] Fakharifar M, Dalvand A, Arezoumandi M, Sharbatdar MK, Chen G, Kheyroddin A. Mechanical properties of high performance fiber reinforced cementitious composites. Construction and Building Materials. 2014;71:510-20. http://dx.doi.org/10.1016/j.conbuildmat.2014.08.068

[14] Vincent T, Ozbakkaloglu T. Influence of concrete strength and confinement method on axial compressive behavior of FRP confined high-and ultra high-strength concrete. Composites Part B: Engineering. 2013;50:413-28.

[15] Ozbakkaloglu T. Behavior of square and rectangular ultra high-strength concrete-filled FRP tubes under axial compression. Composites Part B: Engineering. 2013;54:97-111.

[16] Ozbakkaloglu T, Saatcioglu M. Seismic behavior of high-strength concrete columns confined by fiber-reinforced polymer tubes. Journal of Composites for Construction. 2006;10(6):538-49.

[17] Zohrevand P, Mirmiran A. Behavior of ultrahigh-performance concrete confined by fiber-reinforced polymers. Journal of Materials in Civil Engineering. 2011;23(12):1727-34.

[18] Zohrevand P, Mirmiran A. Cyclic behavior of hybrid columns made of ultra high performance concrete and fiber reinforced polymers. Journal of Composites for Construction. 2012;16(1):91-9.

[19] Li B, Zohrevand P, Mirmiran A. Cyclic behavior of FRP concrete bridge pier frames. Journal of Bridge Engineering. 2012;18(5):429-38.

[20] Shi Y, Zohrevand P, Mirmiran A. Assessment of cyclic behavior of hybrid FRP concrete columns. Journal of Bridge Engineering. 2012;18(6):553-63.

[21] El Chabib H, Nehdi M, El Naggar M-H. Behavior of SCC confined in short GFRP tubes. Cement and Concrete Composites. 2005;27(1):55-64. 
[22] Yu T, Fang X, Teng J. FRP-Confined Self-Compacting Concrete under Axial Compression. Journal of Materials in Civil Engineering. 2013.

[23] Xiao J, Huang Y, Yang J, Zhang C. Mechanical properties of confined recycled aggregate concrete under axial compression. Construction and Building Materials. 2012;26(1):591-603.

[24] Zhao J, Yu T, Teng J. Stress-Strain Behavior of FRP-Confined Recycled Aggregate Concrete. Journal of Composites for Construction. 2014.

[25] Priestley M, Seible F. Design of seismic retrofit measures for concrete and masonry structures. Construction and Building Materials. 1995;9(6):365-77.

[26] Fakharifar M, Chen G, Sneed L, Dalvand A. Seismic performance of post-mainshock FRP/steel repaired RC bridge columns subjected to aftershocks. Composites Part B: Engineering. 2015;72:183-98. http://dx.doi.org/10.1016/j.compositesb.2014.12.010

[27] Yan Z, Pantelides CP, Reaveley LD. Posttensioned FRP composite shells for concrete confinement. Journal of Composites for Construction. 2007;11(1):81-90.

[28] Nesheli KN, Meguro K. Seismic retrofitting of earthquake-damaged concrete columns by lateral pretensioning of FRP belts. Proc, 8th US National Conf on Earthquake Engineering: Earthquake Engineering Research Institute (EERI) El Cerrito, CA; 2006.

[29] Fakharifar M, Sharbatdar M, Lin Z, Dalvand A, Sivandi-Pour A, Chen G. Seismic performance and global ductility of RC frames rehabilitated with retrofitted joints by CFRP laminates. Earthquake Engineering and Engineering Vibration. 2014;13(1):59-73. http://dx.doi.org/10.1007/s11803-014-0212-6 [30] Lin Z, Fakhairfar M, Wu C, Chen G, Bevans W, Gunasekaran AVK, et al. Design, Construction and Load Testing of the Pat Daly Road Bridge in Washington County, MO, with Internal Glass Fiber Reinforced Polymers Reinforcement. 2013.

[31] Rousakis TC, Tourtouras IS. RC columns of square section-Passive and active confinement with composite ropes. Composites Part B: Engineering. 2014;58:573-81.

[32] Rousakis TC, Kouravelou KB, Karachalios TK. Effects of carbon nanotube enrichment of epoxy resins on hybrid FRP-FR confinement of concrete. Composites Part B: Engineering. 2014;57:210-8.

[33] Anggawidjaja D, Ueda T, Dai J, Nakai H. Deformation capacity of RC piers wrapped by new fiberreinforced polymer with large fracture strain. Cement and Concrete Composites. 2006;28(10):914-27.

[34] Shimomura T, Phong N. Structural performance of concrete members reinforced with continuous fiber rope. FRPRCS-8 Conference University of Patras, Patras, Greece2007.

[35] Fakharifar M, Chen G, Arezoumandi M, ElGawady M. Hybrid Jacketing for Rapid Repair of Seismically Damaged Reinforced Concrete Columns. Transportation Research Record (TRR): Journal of the Transportation Research Board. 2015;2522:70-8. http://dx.doi.org/10.3141/2522-07

[36] He R, Sneed LH, Belarbi A. Rapid Repair of Severely Damaged RC Columns with Different Damage Conditions: An Experimental Study. International Journal of Concrete Structures and Materials. 2013;7(1):35-50.

[37] Xiao Y, He W, Choi K-k. Confined concrete-filled tubular columns. Journal of structural engineering. 2005;131(3):488-97.

[38] Saatcioglu M, Yalcin C. External prestressing concrete columns for improved seismic shear resistance. Journal of Structural Engineering. 2003;129(8):1057-70.

[39] ElGawady M, Endeshaw M, McLean D, Sack R. Retrofitting of rectangular columns with deficient lap splices. Journal of Composites for Construction. 2009;14(1):22-35.

[40] Fakharifar M, Dalvand A, Sharbatdar M, Chen G, Sneed L. Innovative hybrid reinforcement constituting conventional longitudinal steel and FRP stirrups for improved seismic strength and ductility of RC structures. Front Struct Civ Eng. 2015:1-19. http://dx.doi.org/10.1007/s11709-015-0295-9

[41] Micelli F, Angiuli R, Corvaglia P, Aiello MA. Passive and SMA-activated confinement of circular masonry columns with basalt and glass fibers composites. Composites Part B: Engineering. 2014;67:34862.

[42] Andrawes B, Shin M, Wierschem N. Active confinement of reinforced concrete bridge columns using shape memory alloys. Journal of Bridge Engineering. 2009;15(1):81-9. 
[43] Choi E, Kim J-W, Rhee I, Kang J-W. Behavior and modeling of confined concrete cylinders in axial compression using FRP rings. Composites Part B: Engineering. 2014;58:175-84.

[44] Shin M, Andrawes B. Lateral cyclic behavior of reinforced concrete columns retrofitted with shape memory spirals and FRP wraps. Journal of Structural Engineering. 2010;137(11):1282-90.

[45] Fakharifar M, Chen G, Dalvand A, Shamsabadi A. Collapse Vulnerability and Fragility Analysis of Substandard RC Bridges Rehabilitated with Different Repair Jackets Under Post-mainshock Cascading Events. International Journal of Concrete Structures and Materials. 2015;9(3):345-67. http://dx.doi.org/10.1007/s40069-015-0107-6

[46] Wright T, DesRoches R, Padgett JE. Bridge seismic retrofitting practices in the central and southeastern United States. Journal of Bridge Engineering. 2010;16(1):82-92.

[47] Shin M, Andrawes B. Experimental investigation of actively confined concrete using shape memory alloys. Engineering Structures. 2010;32(3):656-64.

[48] El-Tahan M, Dawood M, Song G. Development of a self-stressing NiTiNb shape memory alloy (SMA)/fiber reinforced polymer (FRP) patch. Smart Materials and Structures. 2015;24(6):065035.

[49] Mastali M, Valente IB, Barros JA, Gonçalves DM. Development of innovative hybrid sandwich panel slabs: Experimental results. Composite Structures. 2015;133:476-98.

[50] Choi E, Cho B-S, Lee S. Seismic retrofit of circular RC columns through using tensioned GFRP wires winding. Composites Part B: Engineering. 2015;83:216-25.

[51] Xiao Y, He W, Mao X, Choi K, Zhu P. Confinement design of CFT columns for improved seismic performance. Proceedings of the International Workshop on Steel and Concrete Composite Construction (IWSCCC-2003): Taipei, China; 2003. p. 217-26.

[52] Xiao Y, Zhang Z, Hu J, Kunnath SK, Guo P. Seismic behavior of CFT column and steel pile footings. Journal of Bridge Engineering. 2011;16(5):575-86.

[53] Fakharifar M, Chen G, Lin Z, Woolsey Z. Behavior and strength of passively confined concrete filled tubes. the 10th US national conference on earthquake engineering: July. Anchorage, AK2014.

[54] Mohamed HM, Abdel-Baky HM, Masmoudi R. Nonlinear Stability Analysis of Concrete-Filled Fiber-Reinforced Polymer-Tube Columns: Experimental and Theoretical Investigation. ACI Structural Journal. 2010;107(6).

[55] Shahawy M, Mirmiran A, Beitelman T. Tests and modeling of carbon-wrapped concrete columns. Composites Part B: Engineering. 2000;31(6):471-80.

[56] Wang Y-h, Nie J-g, Cai C. Numerical modeling on concrete structures and steel-concrete composite frame structures. Composites Part B: Engineering. 2013;51:58-67.

[57] Wong Y, Yu T, Teng J, Dong S. Behavior of FRP-confined concrete in annular section columns. Composites Part B: Engineering. 2008;39(3):451-66.

[58] Idris Y, Ozbakkaloglu T. Seismic behavior of high-strength concrete-filled FRP tube columns. Journal of Composites for Construction. 2013;17(6).

[59] Abdelkarim OI, ElGawady MA. Analytical and Finite-Element Modeling of FRP-Concrete-Steel Double-Skin Tubular Columns. Journal of Bridge Engineering. 2014.

[60] Han L-H, Tao Z, Liao F-Y, Xu Y. Tests on cyclic performance of FRP-concrete-steel double-skin tubular columns. Thin-Walled Structures. 2010;48(6):430-9.

[61] Belarbi A, Bae S-W. An experimental study on the effect of environmental exposures and corrosion on RC columns with FRP composite jackets. Composites Part B: Engineering. 2007;38(5):674-84.

[62] Wang J-Y, Yang Q-B. Investigation on compressive behaviors of thermoplastic pipe confined concrete. Construction and Building Materials. 2012;35:578-85.

[63] Pando MA, Ealy CD, Filz GM, Lesko J, Hoppe E. A Laboratory and Field Study of Composite Piles for Bridge Substructures. FHWA-HRT-04-0432006.

[64] Karbhari VM. Durability of composites for civil structural applications: Elsevier; 2007.

[65] Naghibdehi MG, Sharbatdar M, Mastali M. Repairing reinforced concrete slabs using composite layers. Materials \& Design. 2014;58:136-44.

[66] Kurt CE. Concrete filled structural plastic columns. Journal of the Structural Division. 1978;104(1):55-63. 
[67] Toutanji H, Saafi M. Durability studies on concrete columns encased in PVC-FRP composite tubes. Composite structures. 2001;54(1):27-35.

[68] Toutanji H, Saafi M. Stress-strain behavior of concrete columns confined with hybrid composite materials. Materials and Structures. 2002;35(6):338-47.

[69] Soliman S, El-kareim A. Behavior of long confined concrete column. Ain Shams Engineering Journal. 2011;2(3):141-8.

[70] Gupta PK. Confinement of concrete columns with unplasticized Poly-vinyl chloride tubes. International Journal of Advanced Structural Engineering. 2013;5(1):19.

[71] Wang J, Yang Q. Experimental study on Mechanical Properties of concrete confined with plastic Pipe. ACI Materials Journal. 2010;107(2).

[72] Nowack R, Otto OI, Braun EW. „60 Jahre Erfahrungen mit Rohrleitungen aus weichmacherfreiem Polyvinylchlorid (PVC-U). KRV Nachrichten. 1995:1-95.

[73] Awham M, Salih ZGM. A Study of some Mechanical Behavior on a Thermoplastic Material.

[74] Al-Malaika S, Golovoy A, Wilkie CA. Chemistry and technology of polymer additives: Blackwell Science; 1999.

[75] Titow WV. PVC technology: Springer; 1984.

[76] Gupta PK, Verma VK. Study of concrete-filled unplasticized poly-vinyl chloride tubes in marine environment. Proceedings of the Institution of Mechanical Engineers, Part M: Journal of Engineering for the Maritime Environment. 2014:1475090214560448.

[77] Gathimba Naftary K, Oyawa Walter O, Mang'uriu Geoffrey N. Compressive Strength Characteristics of Concrete-Filled Plastic Tubes Short Columns. International Journal of Science and Research (IJSR). 2014;3(9):2168-74.

[78] Jiang S-F, Ma S-L, Wu Z-Q. Experimental study and theoretical analysis on slender concrete-filled CFRP-PVC tubular columns. Construction and Building Materials. 2014;53:475-87.

[79] Harries KA, Carey SA. Shape and "gap" effects on the behavior of variably confined concrete. Cement and Concrete Research. 2003;33(6):881-90.

[80] ASTMC39/C39M. Standard Test Method for Compressive Strength of Cylindrical Concrete Specimens. West Conshohocken (PA): ASTM; 2012. p. 7.

[81] ASTMC496/C496M. Standard test method for splitting tensile strength of cylindrical concrete. West Conshohocken (PA): ASTM; 2011. p. 5.

[82] ASTMC78/C78M. Standard test method for flexural strength of concrete (using simple beam with third-point loading). West Conshohocken (PA): ASTM; 2010. p. 4.

[83] ASTMD1785. Standard Specification for Poly(Vinyl Chloride) (PVC) Plastic Pipe, Schedules 40, 80, and 120. PVC, Schedule. West Conshohocken: ASTM; 2012. p. 11.

[84] ASTMD3039/D3039M. Standard test method for tensile properties of fiber resin composites. West Conshohocken (PA): ASTM; 2012.

[85] ASTMD638. Standard Test Method for Tensile Properties of Plastics. ASTM International. West Conshohocken (PA)2008.

[86] Vincent T, Ozbakkaloglu T. Influence of fiber orientation and specimen end condition on axial compressive behavior of FRP-confined concrete. Construction and Building materials. 2013;47:814-26.

[87] Tasdemir M, Tasdemir C, Akyüz S, Jefferson A, Lydon F, Barr B. Evaluation of strains at peak stresses in concrete: a three-phase composite model approach. Cement and Concrete Composites. 1998;20(4):301-18.

[88] Lam L, Teng J. Strength models for fiber-reinforced plastic-confined concrete. Journal of Structural Engineering. 2002;128(5):612-23.

[89] Ozbakkaloglu T. Compressive behavior of concrete-filled FRP tube columns: Assessment of critical column parameters. Engineering Structures. 2013;51:188-99.

[90] Chen J, Ai J, Stratford T. Effect of geometric discontinuities on strains in FRP-wrapped columns. Journal of Composites for Construction. 2009.

[91] Fanggi BAL, Ozbakkaloglu T. Compressive behavior of aramid FRP-HSC-steel double-skin tubular columns. Construction and Building Materials. 2013;48:554-65. 
[92] Samaan M, Mirmiran A, Shahawy M. Model of concrete confined by fiber composites. Journal of structural engineering. 1998;124(9):1025-31.

[93] Ozbakkaloglu T, Akin E. Behavior of FRP-confined normal-and high-strength concrete under cyclic axial compression. Journal of Composites for Construction. 2011;16(4):451-63.

[94] Yan X, Yali S. Impact behaviors of CFT and CFRP confined CFT stub columns. Journal of Composites for Construction. 2012;16(6):662-70.

[95] Louk Fanggi B, Ozbakkaloglu T. Behavior of Hollow and Concrete-Filled FRP-HSC and FRP-HSCSteel Composite Columns Subjected to Concentric Compression. Advances in Structural Engineering. 2015;18(5):715-38.

[96] Lim JC, Ozbakkaloglu T. Confinement model for FRP-confined high-strength concrete. Journal of Composites for Construction. 2013;18(4).

[97] Benzaid R, Mesbah H, Chikh NE. FRP-confined concrete cylinders: axial compression experiments and strength model. Journal of Reinforced plastics and composites. 2010;29(16):2469-88.

[98] Bisby LA, Dent AJ, Green MF. Comparison of confinement models for fiber-reinforced polymerwrapped concrete. ACI Structural Journal. 2005;102(1).

[99] Lam L, Teng J. Design-oriented stress-strain model for FRP-confined concrete. Construction and building materials. 2003;17(6):471-89.

[100] Shehata IA, Carneiro LA, Shehata LC. Strength of short concrete columns confined with CFRP sheets. Materials and Structures. 2002;35(1):50-8.

[101] Wei Y-Y, Wu Y-F. Unified stress-strain model of concrete for FRP-confined columns. Construction and Building Materials. 2012;26(1):381-92.

[102] Youssef MN, Feng MQ, Mosallam AS. Stress-strain model for concrete confined by FRP composites. Composites Part B: Engineering. 2007;38(5):614-28. 
Table 1. Test metrics of cylinder specimens

\begin{tabular}{|c|c|c|c|c|c|c|}
\hline Confinement type & $\begin{array}{c}D \\
(\mathrm{~mm})\end{array}$ & $\begin{array}{c}H \\
(\mathrm{~mm})\end{array}$ & FRP type & FRP layers & PVC tube & $\begin{array}{c}\text { No. of } \\
\text { specimens }\end{array}$ \\
\hline \multirow[t]{4}{*}{ FW } & \multirow{4}{*}{152} & \multirow{4}{*}{305} & \multirow{2}{*}{ Carbon } & 1 & & 5 \\
\hline & & & & 3 & & 3 \\
\hline & & & \multirow{2}{*}{ E-Glass } & 1 & & 3 \\
\hline & & & & 3 & & 3 \\
\hline CFPT & $168^{*}$ & 305 & & & Grey Schedule 40 & 5 \\
\hline \multirow[t]{5}{*}{ CCFPT } & \multirow{4}{*}{$168^{*}$} & \multirow{4}{*}{305} & \multirow{2}{*}{ Carbon } & 1 & Grey Schedule 40 & 4 \\
\hline & & & & 3 & Grey Schedule 40 & 3 \\
\hline & & & \multirow{2}{*}{ E-Glass } & 1 & Grey Schedule 40 & 7 \\
\hline & & & & 3 & Grey Schedule 40 & 3 \\
\hline & & & & & Total & 36 \\
\hline
\end{tabular}

Outside diameter of PVC tube with a wall thickness of $7.11 \mathrm{~mm}$. 
Table 2. Fresh and hardened concrete properties

\begin{tabular}{lc}
\hline Property & Cylinder specimens \\
\hline Air content $(\%)$ & 1.3 \\
Slump (mm) & 92 \\
Unit weight $\left(\mathrm{kg} / \mathrm{m}^{3}\right)$ & 2400 \\
Tensile split cylinder strength (MPa) & $2.9^{\mathrm{a}}$ \\
Flexural strength (modulus of rupture) (MPa) & $3.4^{\mathrm{b}}$ \\
Compressive strength (MPa) & $49.5^{\mathrm{a}}$ \\
\hline &
\end{tabular}


Table 3. Material properties of FRP sheets*

\begin{tabular}{|c|c|c|c|c|c|c|c|}
\hline \multirow[b]{2}{*}{ Type } & \multirow[b]{2}{*}{$\begin{array}{c}\text { Nominal } \\
\text { fiber } \\
\text { thickness, } \\
t_{f}(\mathrm{~mm} / \mathrm{ply}) \\
\end{array}$} & \multicolumn{3}{|c|}{ Manufacturer specified } & \multicolumn{3}{|c|}{ Measured with flat FRP cupon tests } \\
\hline & & $\begin{array}{l}\text { Tensile } \\
\text { strength, } \\
f_{f}(\mathrm{MPa})\end{array}$ & $\begin{array}{c}\text { Elastic } \\
\text { Modulus, } \\
E_{f}(\mathrm{GPa})\end{array}$ & $\begin{array}{c}\text { Ultimate } \\
\text { tensile strain, } \\
\varepsilon_{f}(\%)\end{array}$ & $\begin{array}{c}\text { Tensile } \\
\text { strength, } \\
f_{f r p}(\mathrm{MPa})\end{array}$ & $\begin{array}{c}\text { Elastic } \\
\text { Modulus, } \\
E_{f r p}(\mathrm{GPa})\end{array}$ & $\begin{array}{c}\text { Ultimate } \\
\text { tensile strain, } \\
\varepsilon_{f r p}(\%)\end{array}$ \\
\hline E-Glass & 0.373 & 1517 & 72.4 & 2.10 & 1449 & 79.18 & 1.85 \\
\hline CFRP & 0.165 & 3800 & 227 & 1.67 & 3421 & 251 & 1.37 \\
\hline
\end{tabular}

* All FRP materials were unidirectional fabrics. 
Table 4. Tensile properties of PVC dogbone specimens under tension

\begin{tabular}{|c|c|c|c|c|c|c|}
\hline $\begin{array}{c}\text { PVC } \\
\text { specimen }\end{array}$ & $\begin{array}{c}\text { Thicknes, } \\
t(\mathrm{~mm})\end{array}$ & $\begin{array}{l}\text { Ultimate } \\
\text { strength, } \\
f_{u}(\mathrm{MPa})\end{array}$ & $\begin{array}{l}\text { Modulus of } \\
\text { elasticity, } \\
E(\mathrm{GPa})\end{array}$ & $\begin{array}{l}\text { Yield strength } \\
\text { at } 0.2 \% \text { offset, } \\
f_{\text {__offset }}(\mathrm{MPa})\end{array}$ & $\begin{array}{c}\text { Ultimate } \\
\text { fracture strain, } \\
\varepsilon_{u}(\%)\end{array}$ & $\begin{array}{c}\text { Poisson's } \\
\text { ratio, } \\
v\end{array}$ \\
\hline Schedule 40 & 7.11 & 50.36 & 4.03 & 41.26 & 46 & 0.419 \\
\hline
\end{tabular}


Table 5. Measured properties of PVC tubes under axial compression

\begin{tabular}{ccccccc}
\hline PVC tube & $\begin{array}{c}\text { Tube } \\
\text { diameter, } \\
D_{t}(\mathrm{~mm})\end{array}$ & $\begin{array}{c}\text { Thicknes, } \\
t(\mathrm{~mm})\end{array}$ & $\begin{array}{c}\text { Peak axial load, } \\
P_{t}(\mathrm{kN})\end{array}$ & $\begin{array}{c}\text { Yield stress } \\
(\mathrm{MPa})\end{array}$ & $\begin{array}{c}\text { Ultimate } \\
\text { strength } \\
(\mathrm{MPa})\end{array}$ & $\begin{array}{c}\text { Axial strain } \\
\text { at peak } \\
(\%)\end{array}$ \\
\hline $\begin{array}{c}\text { Hollow PVC } \\
\text { Schedule 40 }\end{array}$ & 168.3 & 7.11 & 208.5 & 41.3 & 50.93 & 4.27 \\
\hline
\end{tabular}


Table 6. Test results of cylinder specimens

\begin{tabular}{|c|c|c|c|c|c|c|c|c|c|c|c|}
\hline $\begin{array}{c}\text { Confinement } \\
\text { type }\end{array}$ & $\begin{array}{c}\text { Confinement } \\
\text { detail }\end{array}$ & $\begin{array}{c}\text { Specimen } \\
\text { designation }\end{array}$ & $f_{l u} / f_{c o}^{\prime}$ & $f_{l u, a} / f^{\prime}{ }_{c o}$ & $\begin{array}{c}f_{c c}^{\prime} \\
(\mathrm{MPa})\end{array}$ & $\begin{array}{c}f_{c u}^{\prime} \\
(\mathrm{MPa})\end{array}$ & $\begin{array}{c}\varepsilon_{c u} \\
(\%)\end{array}$ & $\begin{array}{c}\varepsilon_{h, \text { rup }} \\
(\%)\end{array}$ & $f_{c o}^{\prime} / f_{c o}^{\prime}$ & $\varepsilon_{c u} / \varepsilon_{c o}$ & $k_{\varepsilon}$ \\
\hline \multirow{14}{*}{ 齐 } & \multirow{5}{*}{1 ply CFRP } & FW-1C\#1 & 0.15 & 0.12 & 65.0 & 60.4 & 0.94 & 1.11 & 1.30 & 3.79 & \multirow{5}{*}{0.70} \\
\hline & & FW-1C\#2 & 0.15 & 0.11 & 67.3 & 65.3 & 0.91 & 1.04 & 1.35 & 3.67 & \\
\hline & & FW-1C\#3 & 0.15 & 0.08 & 63.5 & 54.6 & 0.76 & 0.71 & 1.27 & 3.06 & \\
\hline & & FW-1C\#4 & 0.15 & 0.11 & 64.9 & 40.2 & 0.89 & 1.02 & 1.30 & 3.59 & \\
\hline & & FW-1C\#5 & 0.15 & 0.10 & 62.3 & 58.6 & 0.86 & 0.93 & 1.25 & 3.47 & \\
\hline & \multirow{3}{*}{3 ply CFRP } & $\mathrm{FW}-3 \mathrm{C} \# 1$ & 0.45 & 0.34 & 99.2 & 94.9 & 1.61 & 1.03 & 1.98 & 6.49 & \multirow{3}{*}{0.74} \\
\hline & & FW-3C\#2 & 0.45 & 0.32 & 99.2 & & 1.42 & 0.99 & 1.98 & 5.72 & \\
\hline & & FW-3C\#3 & 0.45 & 0.33 & 94.3 & & 1.46 & 1.01 & 1.89 & 5.88 & \\
\hline & \multirow{3}{*}{1 ply GFRP } & $\mathrm{FW}-1 \mathrm{G} \# 1$ & 0.14 & 0.11 & 63.1 & 53.1 & 1.61 & 1.41 & 1.26 & 6.49 & \multirow{3}{*}{0.71} \\
\hline & & FW-1G\#2 & 0.14 & 0.10 & 63.8 & 44.7 & 1.26 & 1.29 & 1.28 & 5.08 & \\
\hline & & FW-1G\#3 & 0.14 & 0.10 & 63.3 & 54.3 & 1.26 & 1.25 & 1.27 & 5.08 & \\
\hline & \multirow{3}{*}{3 ply GFRP } & FW-3G\#1 & 0.43 & 0.35 & 104.2 & & 2.03 & 1.52 & 2.08 & 8.18 & \multirow{3}{*}{0.85} \\
\hline & & FW-3G\#2 & 0.43 & 0.39 & 102.3 & & 2.20 & 1.68 & 2.05 & 8.87 & \\
\hline & & FW-3G\#3 & 0.43 & 0.35 & 102.1 & & 2.05 & 1.52 & 2.04 & 8.26 & \\
\hline \multirow{5}{*}{ 氜 } & & CFPT-G40\#1 & 0.08 & & 52.6 & 42.0 & 0.60 & & 1.05 & 2.42 & \\
\hline & Sch. 40 PVC & CFPT-G40\#2 & 0.08 & & 49.5 & 39.6 & 0.44 & & 0.99 & 1.81 & \\
\hline & & CFPT-G40\#3 & 0.08 & & 47.8 & 38.2 & 1.01 & & 0.96 & 4.07 & \\
\hline & Sch. 40 PVC with $12 \mathrm{~mm}$. & CFPT-G40-w gap\#1 & 0.08 & & 55.5 & 44.4 & 0.50 & & 1.11 & 2.01 & \\
\hline & gaps at both ends & CFPT-G40-w gap\#2 & 0.08 & & 58.2 & 46.6 & 0.81 & & 1.16 & 3.26 & \\
\hline \multirow{17}{*}{$\sum_{0}^{5}$} & \multirow{4}{*}{ Sch. 40 PVC +1 ply CFRP } & CCFPT-G40-1C\#1 & 0.13 & 0.13 & 69.5 & 66.5 & 1.15 & 1.28 & 1.39 & 4.63 & \multirow{4}{*}{0.75} \\
\hline & & CCFPT-G40-1C\#2 & 0.13 & 0.10 & 61.4 & & 0.86 & 0.98 & 1.23 & 3.47 & \\
\hline & & CCFPT-G40-1C\#3 & 0.13 & 0.10 & 68.3 & & 0.86 & 0.98 & 1.37 & 3.47 & \\
\hline & & CCFPT-G40-1C\#4 & 0.13 & 0.09 & 61.5 & & 0.74 & 0.88 & 1.23 & 2.98 & \\
\hline & \multirow{3}{*}{ Sch. 40 PVC +3 ply CFRP } & CCFPT-G40-3C\#1 & 0.40 & 0.32 & 101.9 & & 1.20 & 1.08 & 2.04 & 4.84 & \multirow{3}{*}{0.83} \\
\hline & & CCFPT-G40-3C\#2 & 0.40 & 0.37 & 90.6 & 86.0 & 1.67 & 1.24 & 1.81 & 6.73 & \\
\hline & & CCFPT-G40-3C\#3 & 0.40 & 0.32 & 94.6 & & 1.26 & 1.09 & 1.89 & 5.08 & \\
\hline & \multirow{3}{*}{ Sch. 40 PVC +1 ply GFRP } & CCFPT-G40-1G\#1 & 0.13 & 0.12 & 68.0 & 58.5 & 1.73 & 1.73 & 1.36 & 6.97 & \multirow{3}{*}{0.88} \\
\hline & & CCFPT-G40-1G\#2 & 0.13 & 0.11 & 72.4 & 60.2 & 1.26 & 1.58 & 1.45 & 5.08 & \\
\hline & & CCFPT-G40-1G\#3 & 0.13 & 0.11 & 67.4 & 57.8 & 1.27 & 1.59 & 1.35 & 5.12 & \\
\hline & \multirow{4}{*}{$\begin{array}{c}\text { Sch. } 40 \text { PVC+1 ply GFRP } \\
\text { with foam between PVC } \\
\text { tube and FRP wrap }\end{array}$} & CCFPT-G40-1G-foam\#1 & 0.13 & 0.13 & 58.7 & 47.0 & 0.62 & 1.84 & 1.17 & 2.50 & \multirow{4}{*}{$0.97^{\mathrm{c}}$} \\
\hline & & CCFPT-G40-1G-foam\#2 & 0.13 & 0.13 & 54.0 & 43.2 & 0.53 & 1.80 & 1.08 & 2.14 & \\
\hline & & CCFPT-G40-1G-foam\#3 & 0.13 & 0.12 & 68.0 & 54.4 & 0.89 & 1.77 & 1.36 & 3.59 & \\
\hline & & CCFPT-G40-1G-foam\#4 & 0.13 & 0.12 & 58.8 & 47.0 & 0.90 & 1.78 & 1.18 & 3.63 & \\
\hline & \multirow{3}{*}{ Sch. 40 PVC +3 ply GFRP } & CCFPT-G40-3G\#1 & 0.39 & 0.35 & 97.9 & & 2.70 & 1.68 & 1.96 & 10.88 & \multirow{3}{*}{0.92} \\
\hline & & CCFPT-G40-3G\#2 & 0.39 & 0.37 & 114.3 & & 3.03 & 1.77 & 2.29 & 12.21 & \\
\hline & & CCFPT-G40-3G\#3 & 0.39 & 0.35 & 103.0 & & 2.71 & 1.67 & 2.06 & 10.92 & \\
\hline
\end{tabular}

${ }^{\mathrm{c}}$ Approximate value only. 
Table 7. Average recorded strain reduction factor, $k_{\varepsilon}$, for various FW and CCFPT specimens.

\begin{tabular}{c|c|c|c}
\hline Confinement type & $k_{\varepsilon}$ & $S D$ & No. \\
\hline All without foam & 0.790 & 0.105 & 27 \\
\hline FRP confined (FW) & 0.744 & 0.091 & 14 \\
$\bullet \quad$ CFRP & 0.715 & 0.088 & 8 \\
$\bullet \quad$ GFRP & 0.781 & 0.087 & 6 \\
\hline FRP + PVC confined (CCFPT) & 0.839 & 0.100 & 13 \\
$\bullet \quad$ CFRP + PVC & 0.785 & 0.106 & 7 \\
$\bullet \quad$ GFRP + PVC & 0.903 & 0.041 & 6 \\
\hline
\end{tabular}


Table 8. Models used to predict strength and strain enhancement ratios of confined specimens.

\begin{tabular}{lll}
\hline Model & Strength enhancement ratio & Strain enhancement ratio \\
\hline Benzaid et al. [97] & $\frac{f_{c c}^{\prime}}{f_{c o}^{\prime}}=1+2.2 \frac{f_{l u, a}}{f_{c o}^{\prime}}$ & $\frac{\varepsilon_{c u}}{\varepsilon_{c o}}=2+7.6 \frac{f_{l u, a}}{f_{c o}^{\prime}}$ \\
Bisby et al. [98] & $f_{c c}^{\prime}=f_{c o}^{\prime}+3.587 f_{l u}^{0.84}$ & $\varepsilon_{c u}=\varepsilon_{c o}+k_{2}\left(\frac{f_{l u}}{f_{c o}^{\prime}}\right)^{\prime}$ \\
Lam and Teng [99] & $\frac{f_{c c}^{\prime}}{f_{c o}^{\prime}}=1+3.3 \frac{f_{l u, a}}{f_{c o}^{\prime}}$ & $\frac{\varepsilon_{c u}}{\varepsilon_{c o}}=1.75+5.53\left(\frac{f_{l u, a}}{f_{c o}^{\prime}}\right)\left(\frac{\varepsilon_{f p p}}{\varepsilon_{c o}}\right)^{0.45}$ \\
Shehata et al. [100] & $\frac{f_{c c}^{\prime}}{f_{c o}^{\prime}}=1+2 \frac{f_{l u}}{f_{c o}^{\prime}}$ & $\frac{\varepsilon_{c u}}{\varepsilon_{c o}}=1+632\left(\frac{f_{l u}}{f_{c o}^{\prime}} \frac{f_{c c}^{\prime}}{E_{f}}\right)^{0.5}$ \\
Ozbakkaloglu and Lim & $f_{c c}^{\prime}=c_{1} f_{c o}^{\prime}+k_{1}\left(f_{l u, a}-f_{l o}\right)$ & $\varepsilon_{c u}=c_{2} \varepsilon_{c o}+k_{2}\left(\frac{K_{l}}{f_{c o}^{\prime}}\right)^{0.9} \varepsilon_{h, r u p}^{1.35}$ \\
[4] & $\frac{f_{c c}^{\prime}}{f_{c o}^{\prime}}=1+2.2\left(\frac{f_{l u}}{f_{c o}^{\prime}}\right)^{0.94}$ & $\frac{\varepsilon_{c u}}{\varepsilon_{c o}}=1.75+12\left(\frac{f_{l u}}{f_{c o}^{\prime}}\right)^{0.75}\left(\frac{f_{30}}{f_{c o}^{\prime}}\right)^{0.62}$ \\
Wei and Wu [101] & $\frac{f_{c c}^{\prime}}{f_{c o}^{\prime}}=1+2.25\left(\frac{f_{l u}}{f_{c o}^{\prime}}\right)^{\frac{5}{4}}$ & $\varepsilon_{c u}=0.003368+0.259\left(\frac{f_{l u}}{f_{c o}^{\prime}}\right)\left(\frac{f_{f p r}}{E_{f f p}}\right)^{\frac{1}{2}}$ \\
Youssef et al. [102] &
\end{tabular}


Table 9. Average absolute error (\%) of strength and strain enhancement ratio predictions.

\begin{tabular}{|c|c|c|c|}
\hline Model & Confinement type & $f_{c o}^{\prime} / f_{c o}^{\prime}$ & $\varepsilon_{c u} / \varepsilon_{c o}$ \\
\hline \multirow[t]{2}{*}{ Benzaid et al. [97] } & FW & 11.8 & 34.1 \\
\hline & CCFPT & 11.7 & 37.4 \\
\hline \multirow[t]{2}{*}{ Bisby et al. [98] } & FW & 3.6 & 25.0 \\
\hline & CCFPT & 7.3 & 34.2 \\
\hline \multirow[t]{2}{*}{ Lam and Teng [99] } & FW & 7.3 & 12.7 \\
\hline & CCFPT & 8.3 & 26.4 \\
\hline \multirow[t]{2}{*}{ Shehata et al. [100] } & FW & 6.3 & 67.1 \\
\hline & CCFPT & 10.1 & 42.4 \\
\hline \multirow{2}{*}{$\begin{array}{l}\text { Ozbakkaloglu } \\
\text { and Lim [4] }\end{array}$} & $\mathrm{FW}$ & 10.2 & 6.97 \\
\hline & CCFPT & 10.5 & 26.3 \\
\hline \multirow[t]{2}{*}{ Wei and Wu [101] } & FW & 3.6 & 16.4 \\
\hline & CCFPT & 6.8 & 32.8 \\
\hline \multirow[t]{2}{*}{ Youssef et al. [102] } & $\mathrm{FW}$ & 9.8 & 12.5 \\
\hline & CCFPT & 14.4 & 29.7 \\
\hline
\end{tabular}



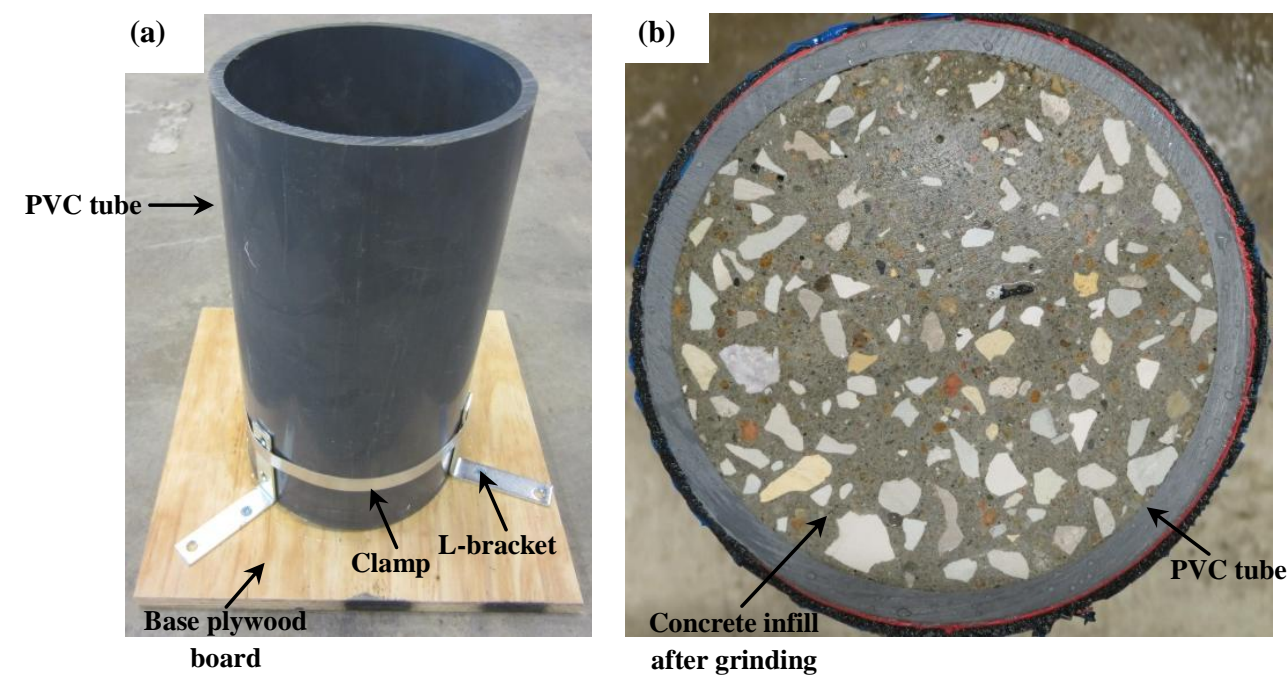

Fig 1. Preparation of cylinder specimens: (a) PVC tube prior to casting; (b) ground end. 


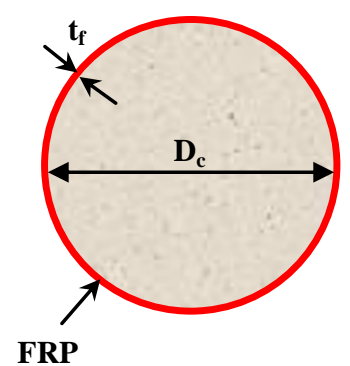

(a) FW

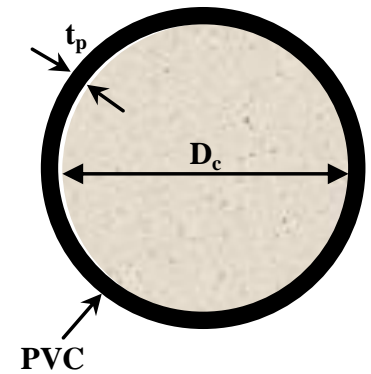

(b) CFPT

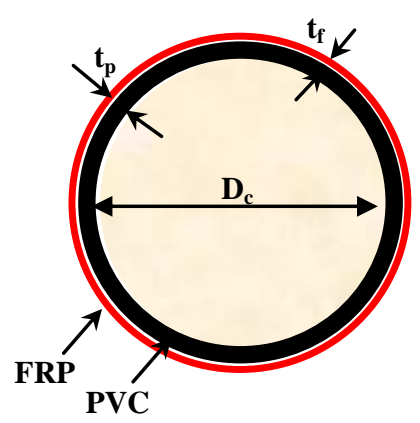

(c) CCFPT

Core concrete diameter, $\mathrm{D}_{\mathrm{c}}: 152 \mathrm{~mm}$

FRP jacket thickness, $\mathrm{t}_{\mathrm{f}}: 1$ or 3 ply

PVC tube thickness: $\mathrm{t}_{\mathrm{p}}: 7.10 \mathrm{~mm}$

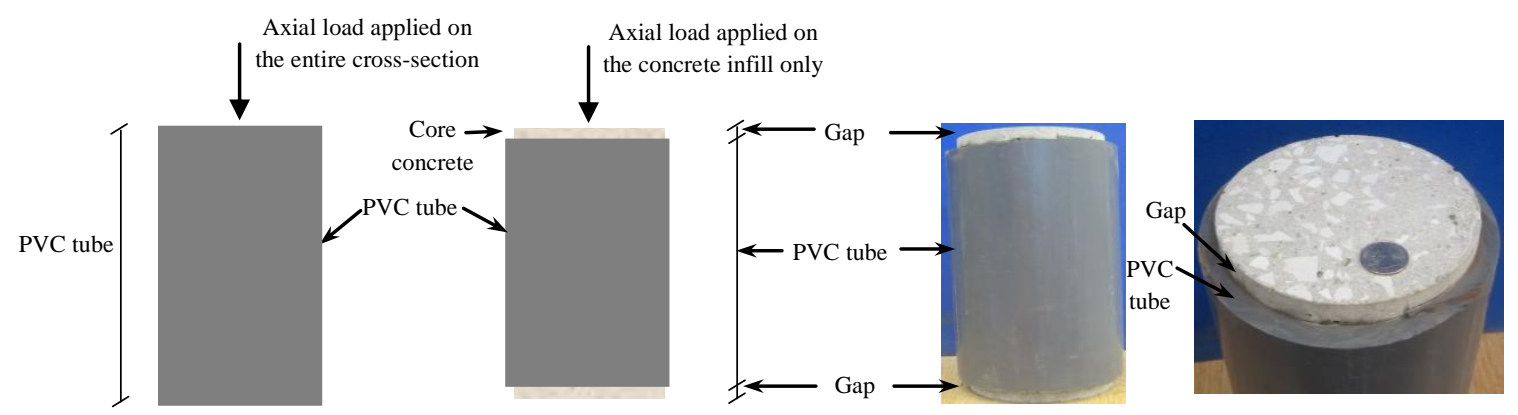

(d) CFPT without and with gaps at both ends (schematic and illustration)

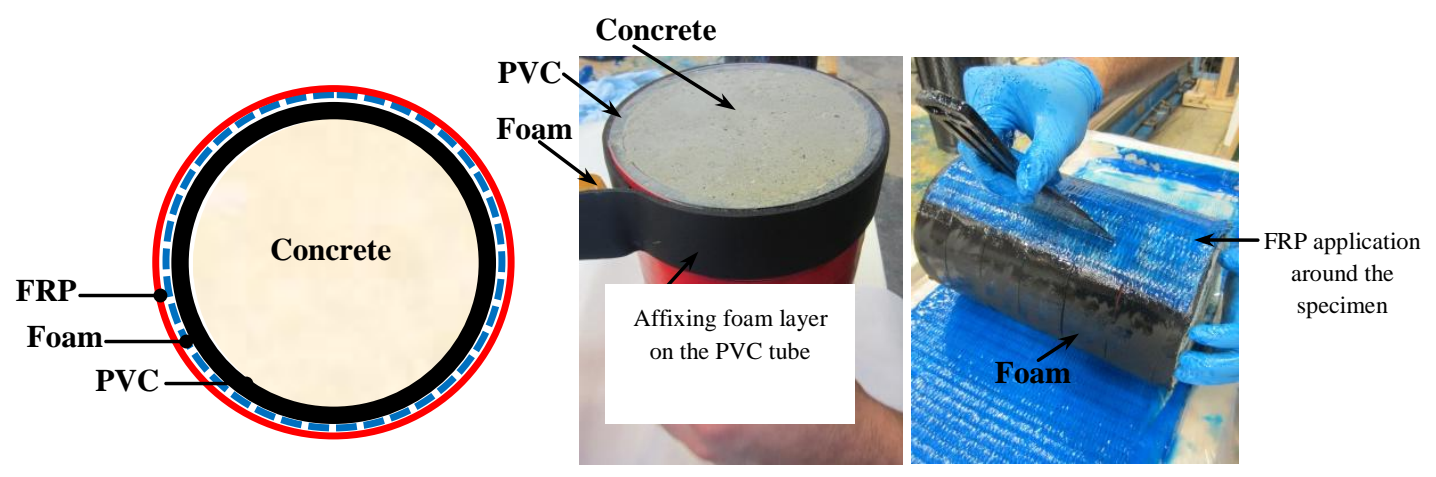

(e) CCFPT with foam layer between PVC tube and FRP wrap (schematic and application)

Fig 2. Details of cylinder specimens: (a) FW; (b) CFPT; (c) CCFPT; (d) CFPT without and with gaps at both ends; and (e) application of a foam layer between PVC tube and FRP wrap in CCFPT system. 

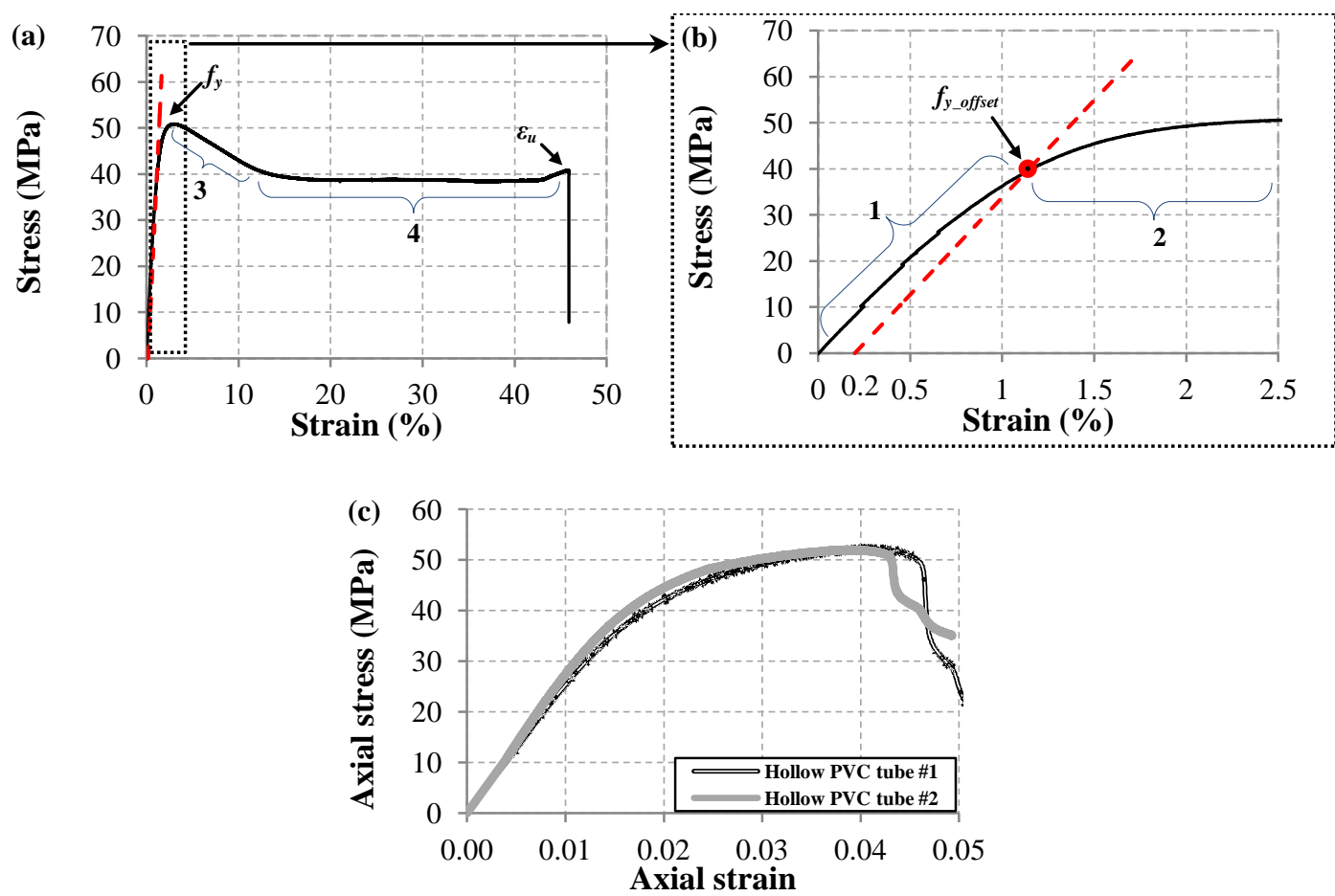

Fig 3. Experimental stress-strain curves: (a) complete tensile curve up to fracture of a dogbone PVC specimen; (b) pre-peak curve with a $0.2 \%$ line offset of the dogbone specimen; and (c) axial compressive behavior of empty PVC tube. 


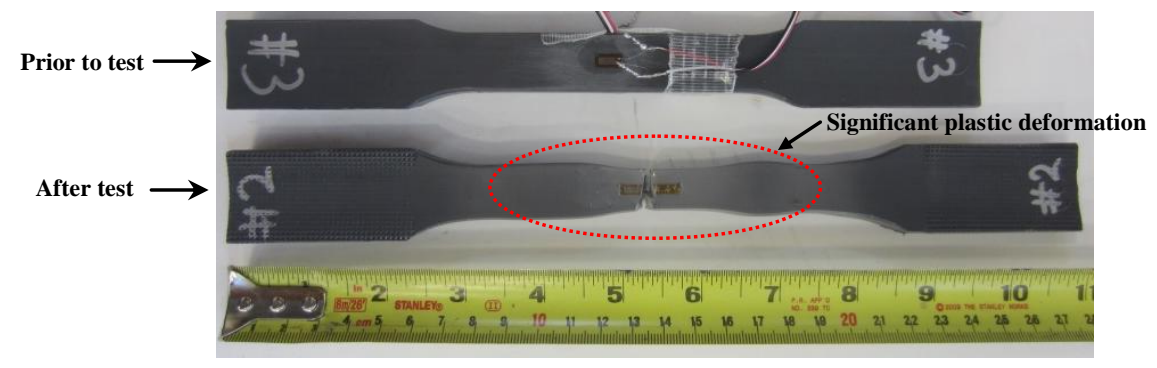

Fig 4. PVC dogbone test specimen prior to and after tensile test. 


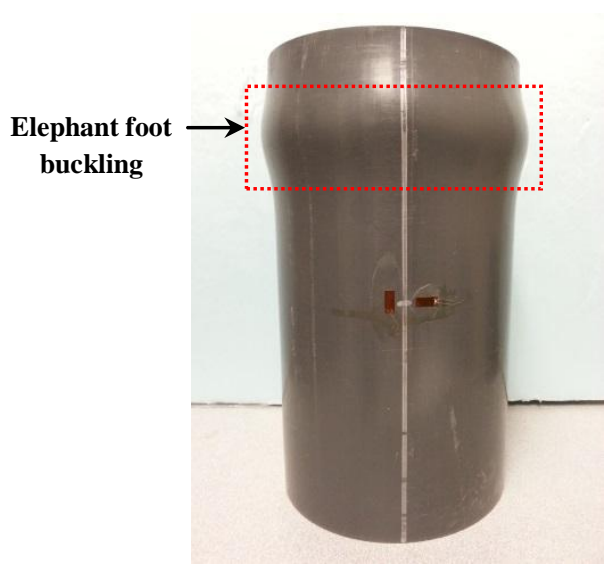

(a)

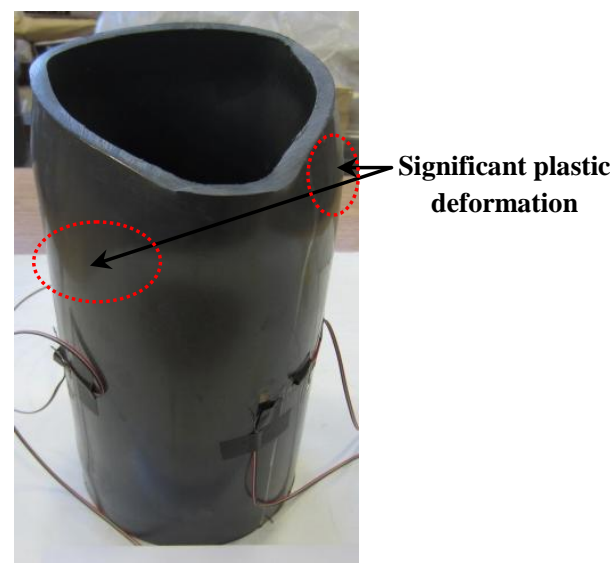

(b)

Fig 5. Hollow PVC tube deformation modes: (a) local elephant foot buckling; (b) global bulging. 


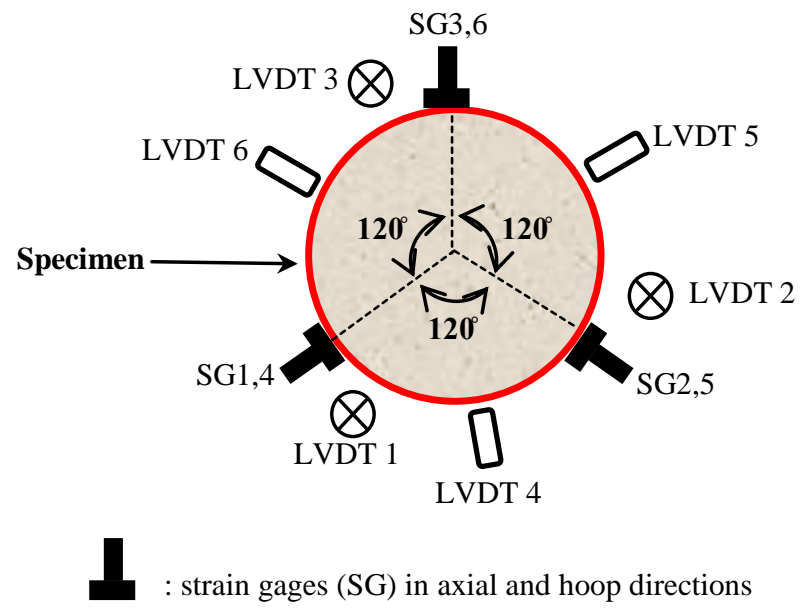

$\bigotimes$ : LVDTs in axial direction

$\square$ : LVDTs in radial direction

(a)

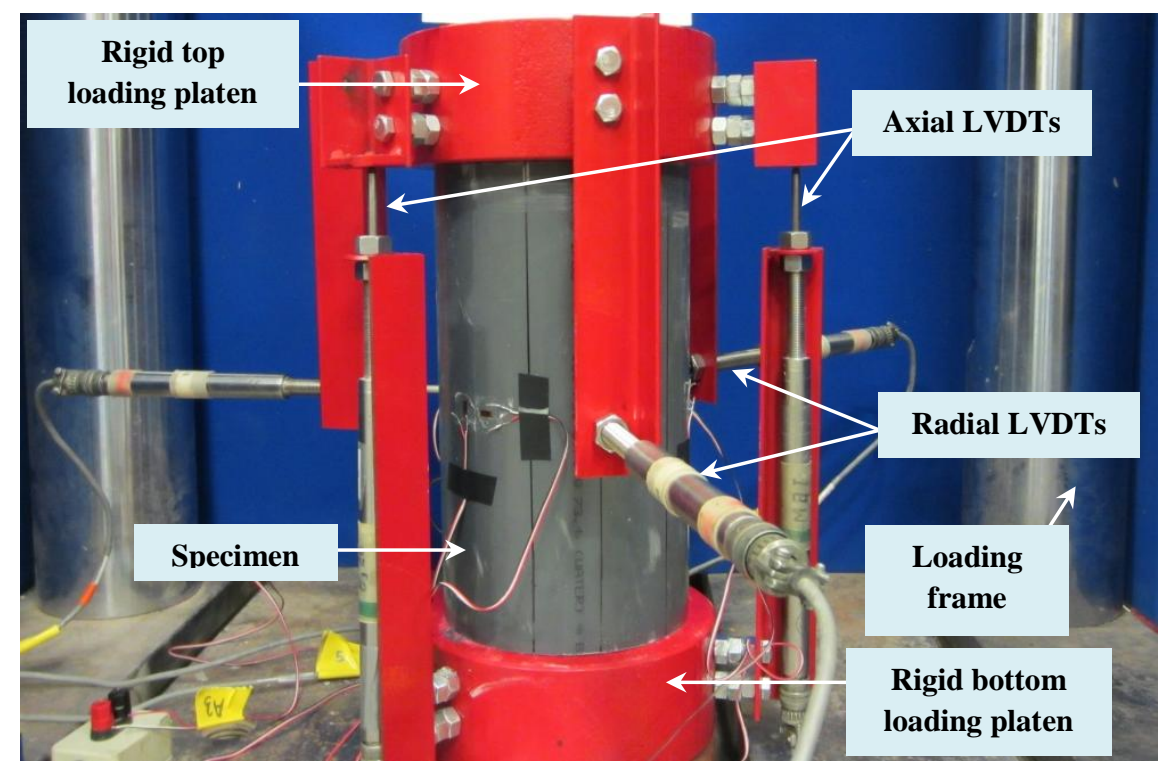

(b)

Fig 6. Uniaxial compression test: (a) instrumentation; (b) setup. 
(a)

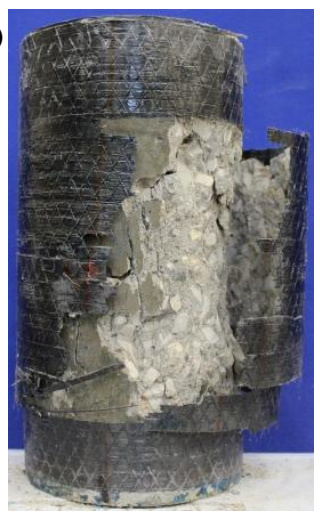

(b)

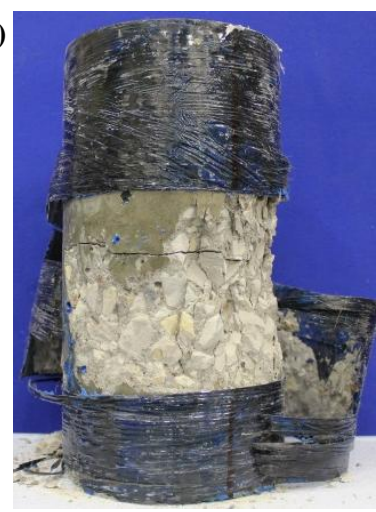

(e)

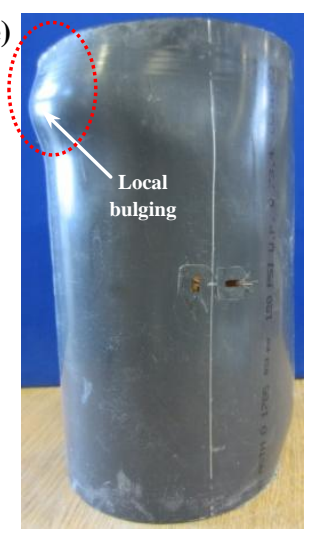

(i)

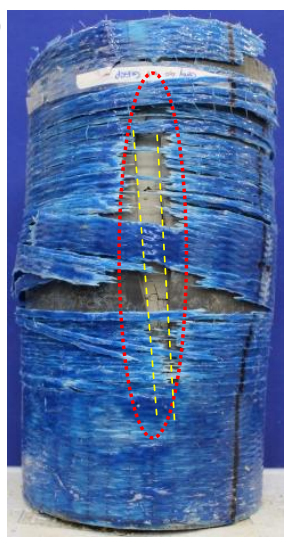

(f)

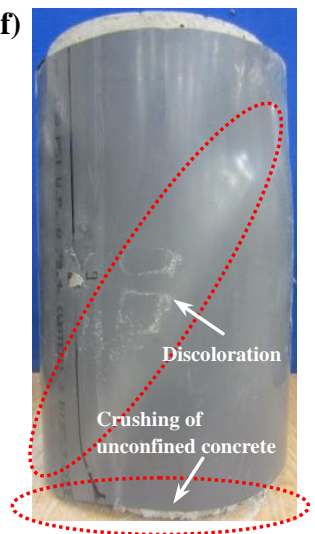

(j)

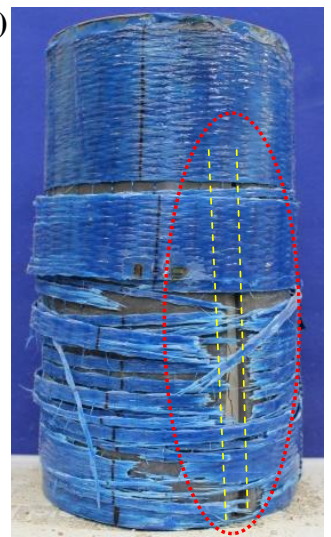

(c)

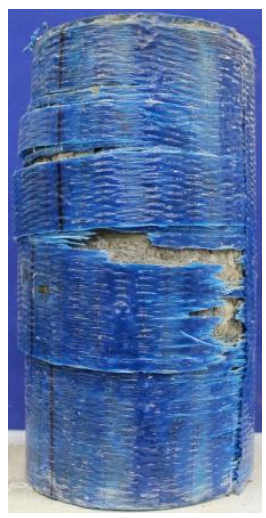

(g)

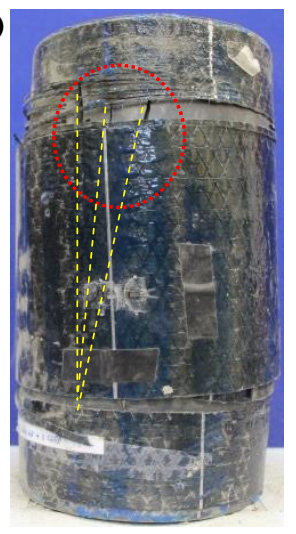

(d)

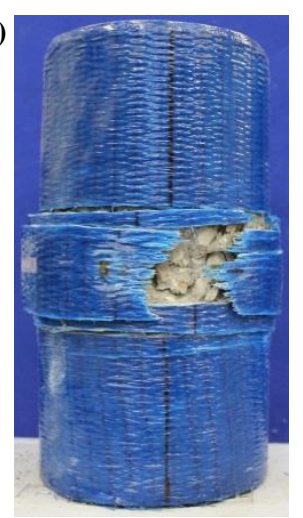

(h)

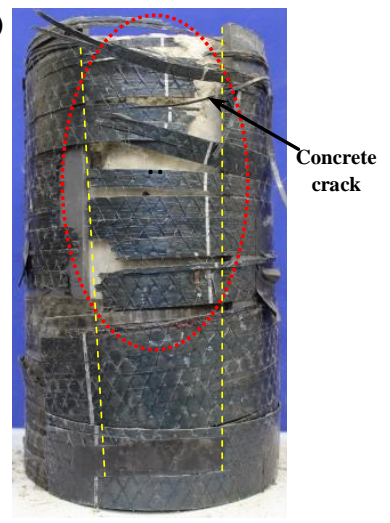

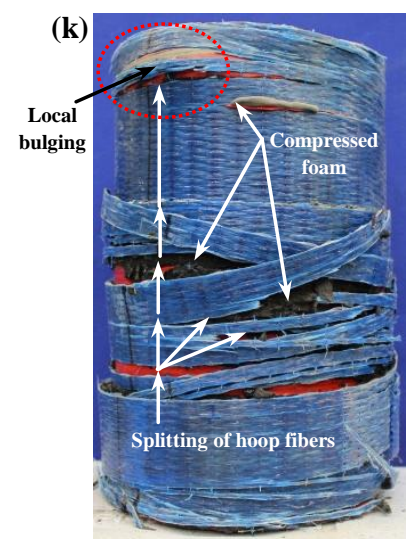

(I)

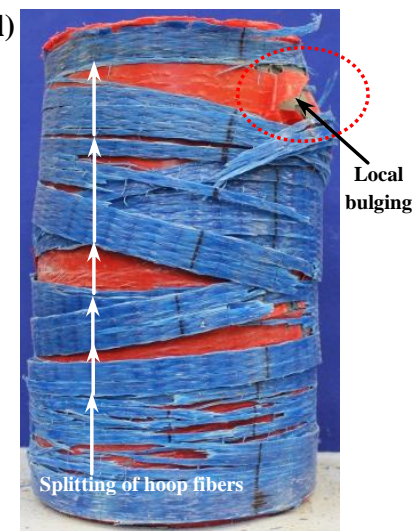

Fig 7. Typical failure of cylinders under axial compression: (a) FW-1C\#1, (b) FW-3C\#2, (c) FW-1G\#1, (d) FW-3G\#3, (e) CFPT-G40\#1, (f) CFPT-G40-w gap\#1, (g) CCFPT-G40-1C\#3, (h) CCFPT-G40-3C\#2, (i) CCFPT-G40-1G\#1, (j) CCFPT-G40-3G\#1, (k) CCFPT-G40-1G-foam\#1, and (l) CCFPT-G40-1Gfoam\#3.

(* Cracks on the PVC tube in CCFPT specimens are marked with yellow dashed lines.) 

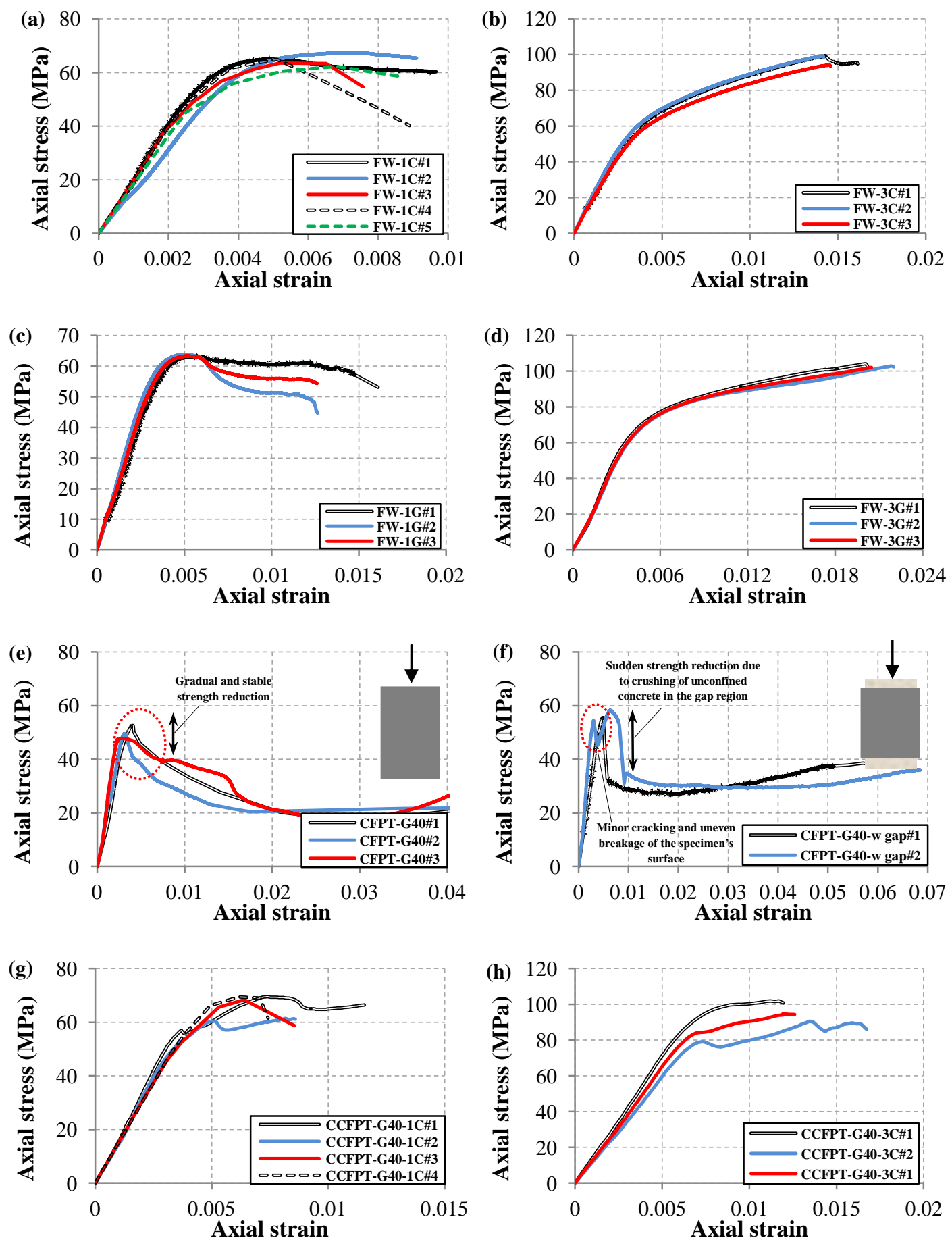

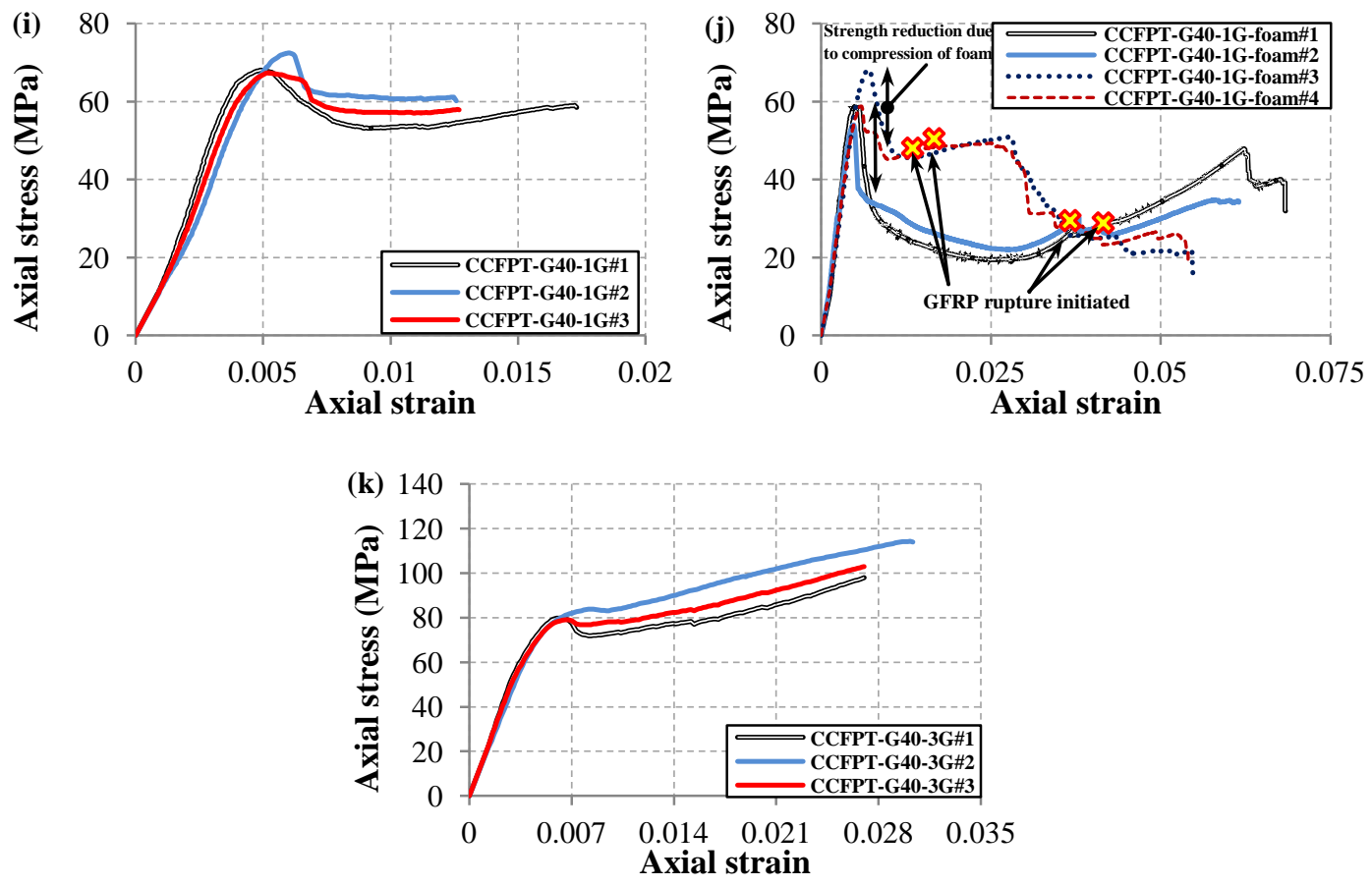

Fig 8. Axial stress-strain behavior of cylinders: (a) FW-1C, (b) FW-3C, (c) FW-1G, (d) FW-3G, (e) CFPT-G40, (f) CFPT-G40-w gap, (g) CCFPT-G40-1C, (h) CCFPT-G40-3C, (i) CCFPT-G40-1G, (j) CCFPT-G40-1G-foam, and (k) CCFPT-G40-3G. 

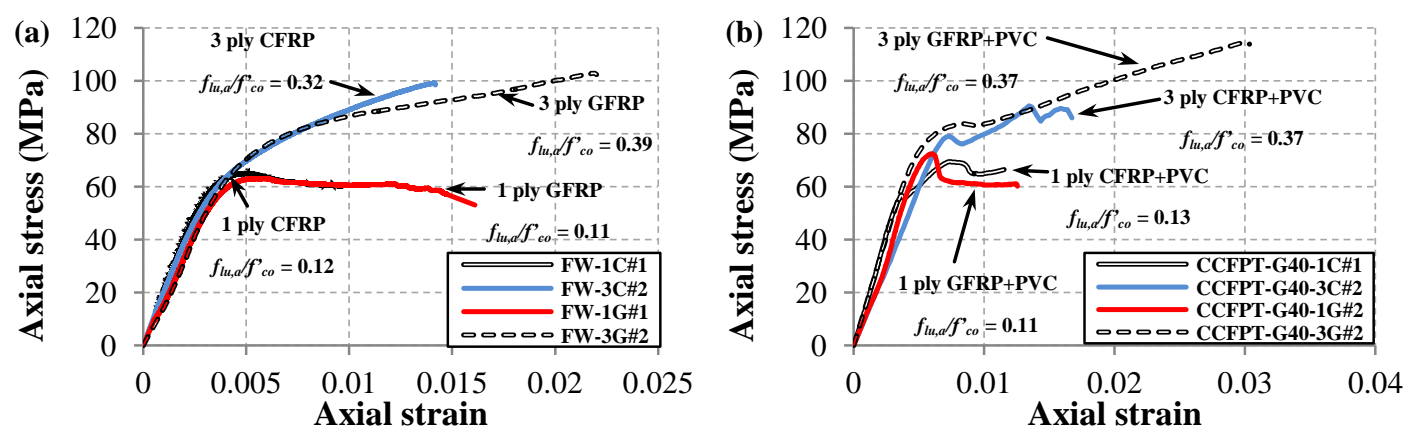

Fig 9. Influence of confinement pressure on stress-strain behavior of test specimens: (a) FW; (b) CCFPT. 

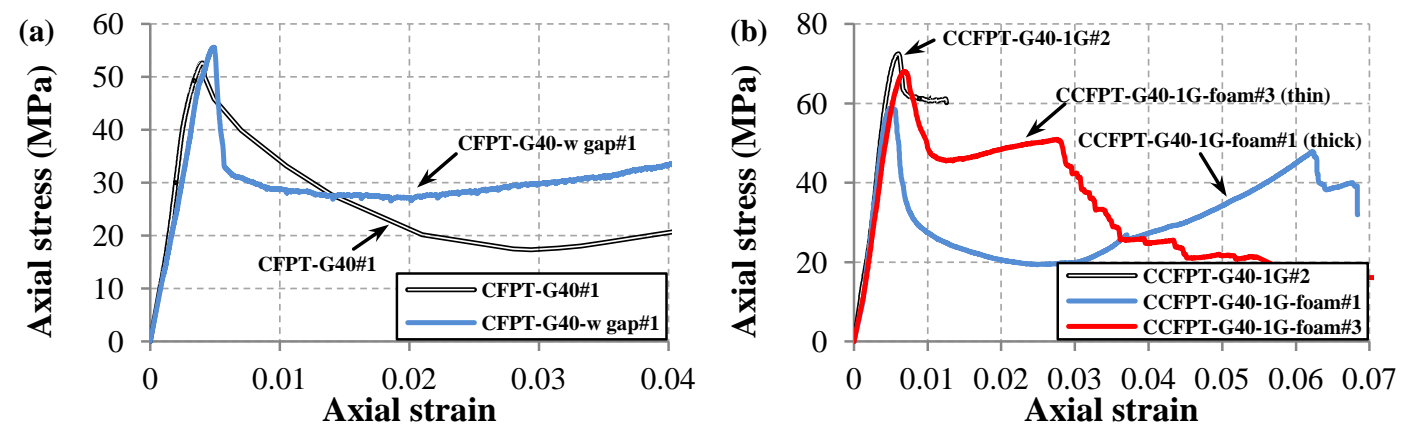

Fig 10. Influence of confinement detail on stress-strain behavior: (a) presence of gap in CFPT specimens; (b) presence of compressible foam in CCFPT specimens. 


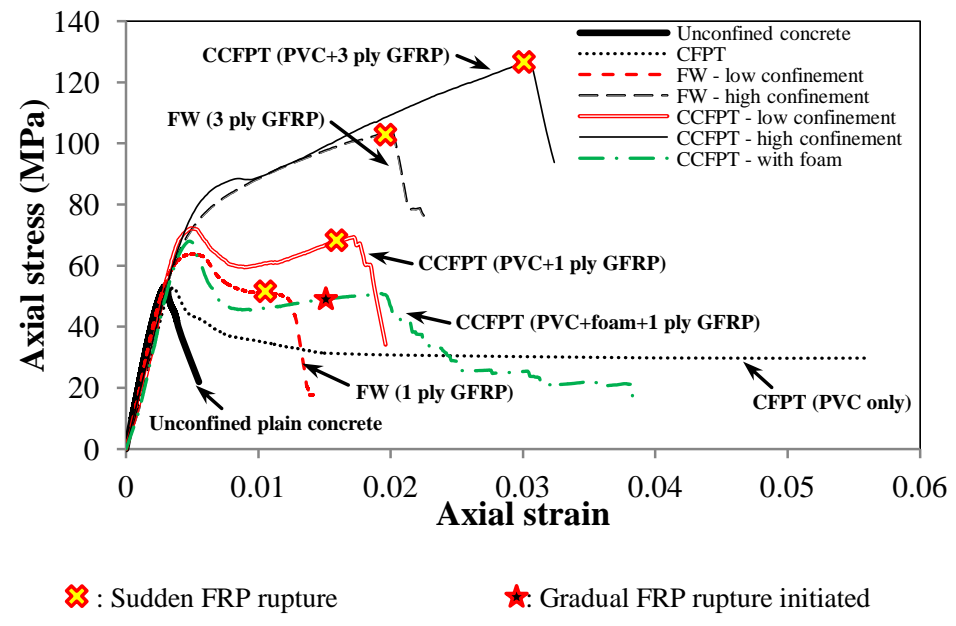

Fig 11. Comparison of representative axial stress-strain behavior of CFPT, FW, and CCFPT specimens. 

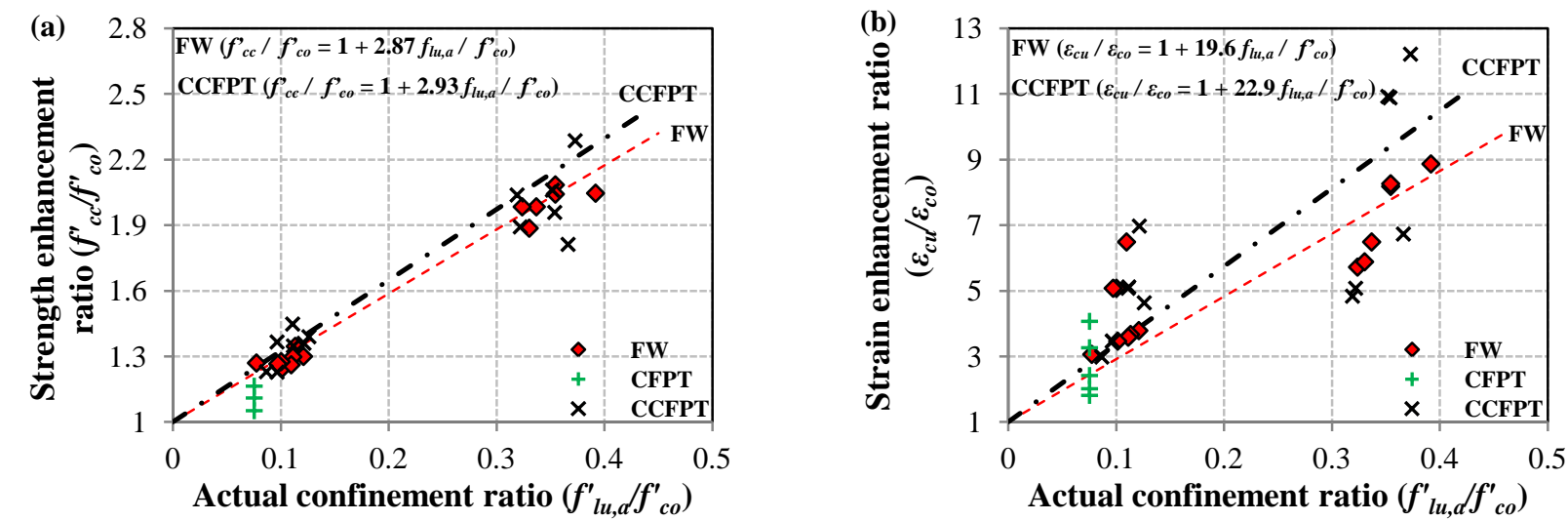

Fig 12. Influence of confinement type on: (a) strength enhancement ratio; (b) strain enhancement ratio. 

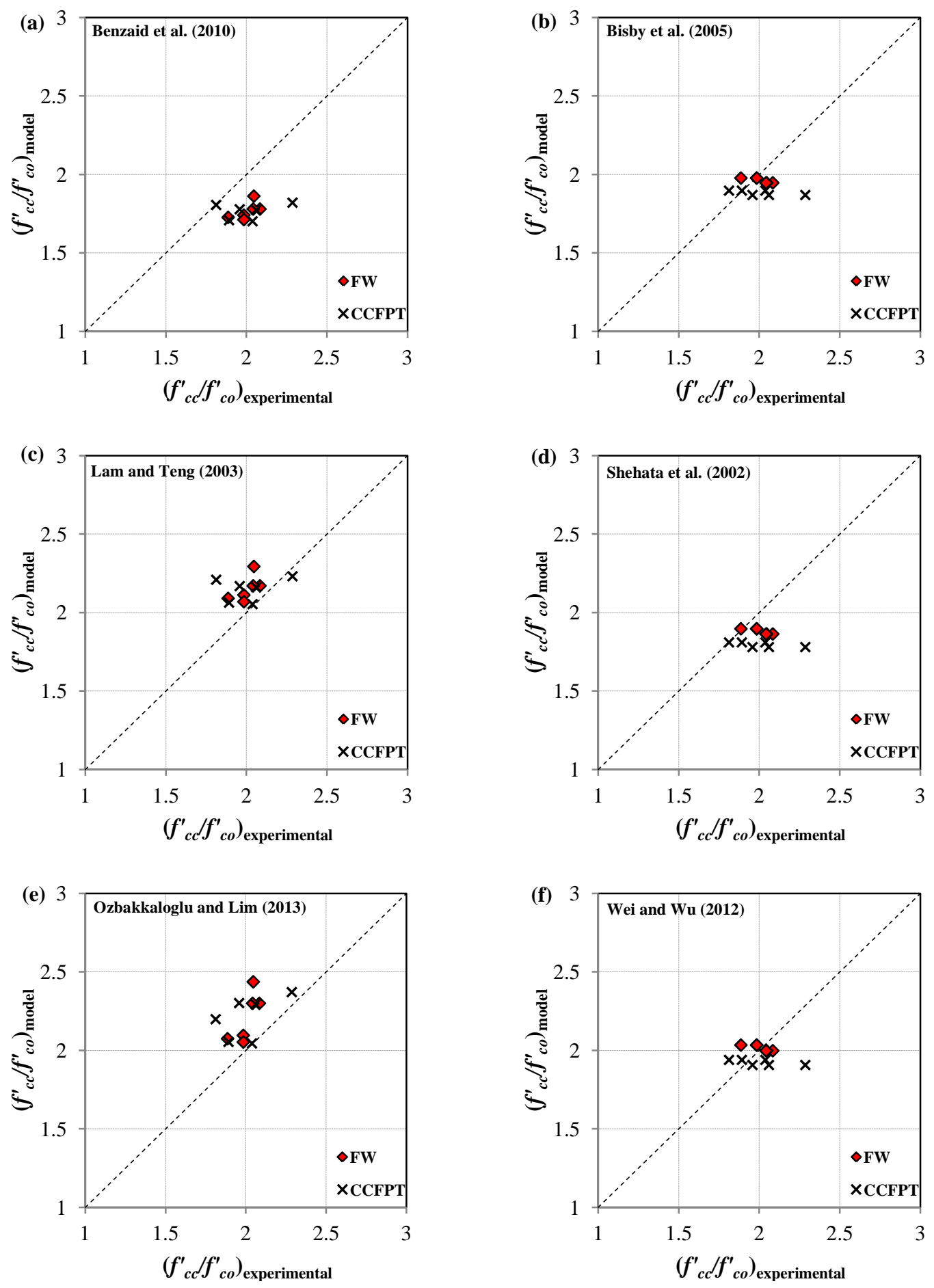

Fig 13. Performance of various confinement models in predicting strength enhancement ratio $\left(f^{\prime}{ }_{c c} / f^{\prime}{ }_{c o}\right)$. 


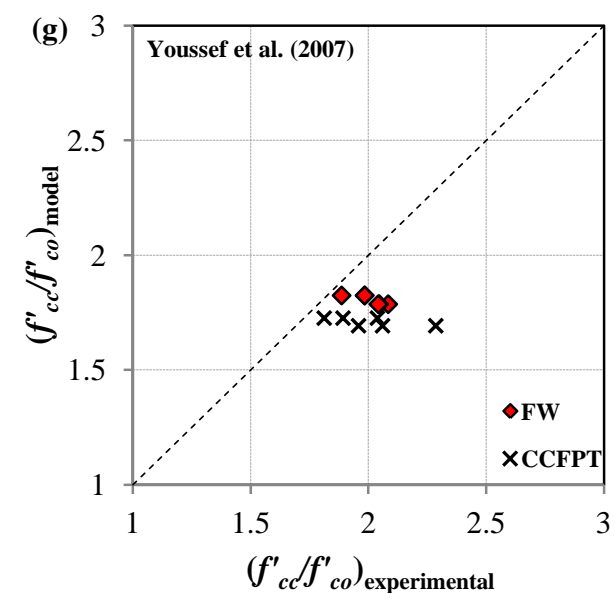

Fig 13. (continued) 

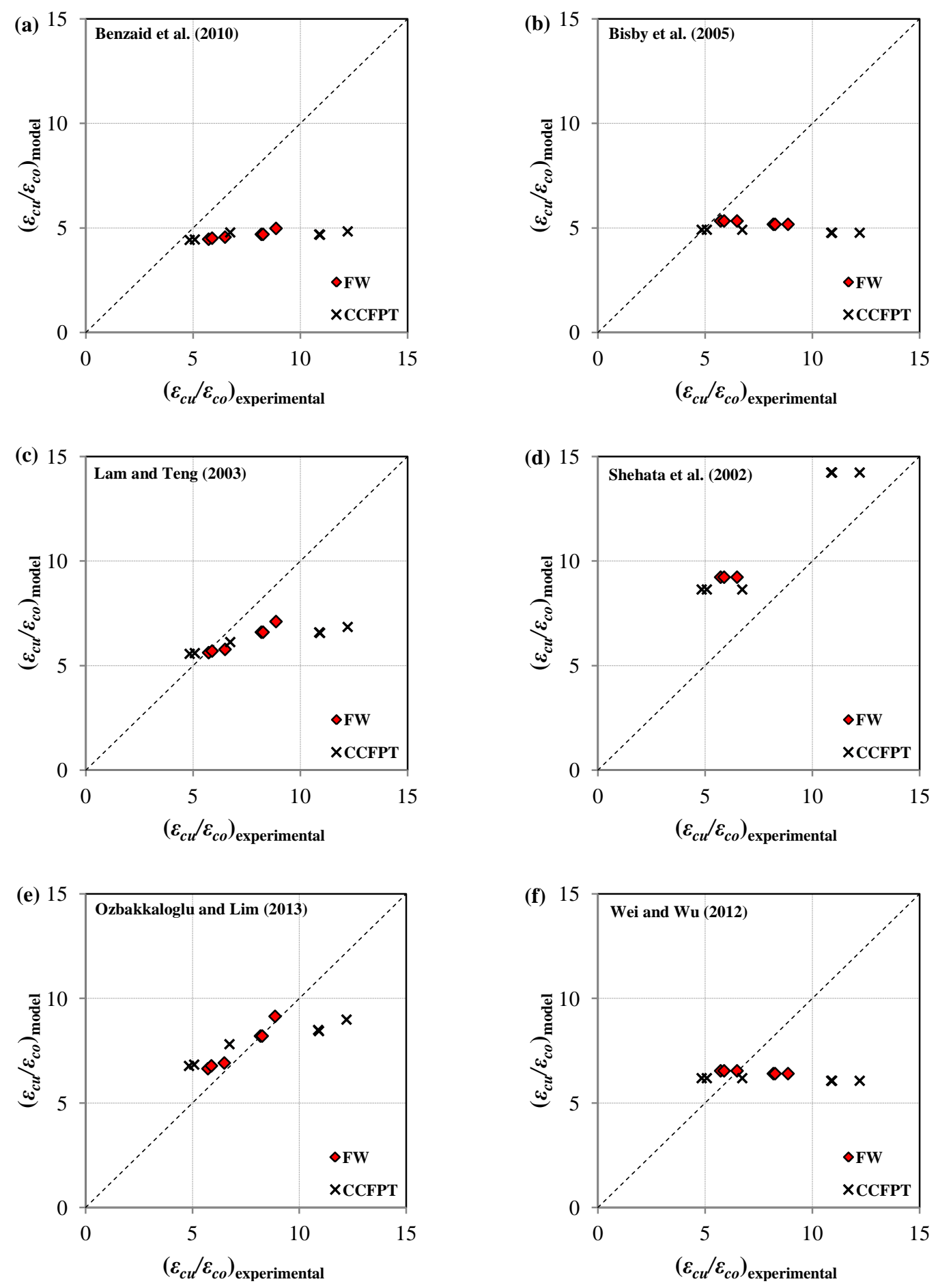

Fig 14. Performance of various confinement models in predicting strain enhancement ratio $\left(\varepsilon_{c u} / \varepsilon_{c o}\right)$. 


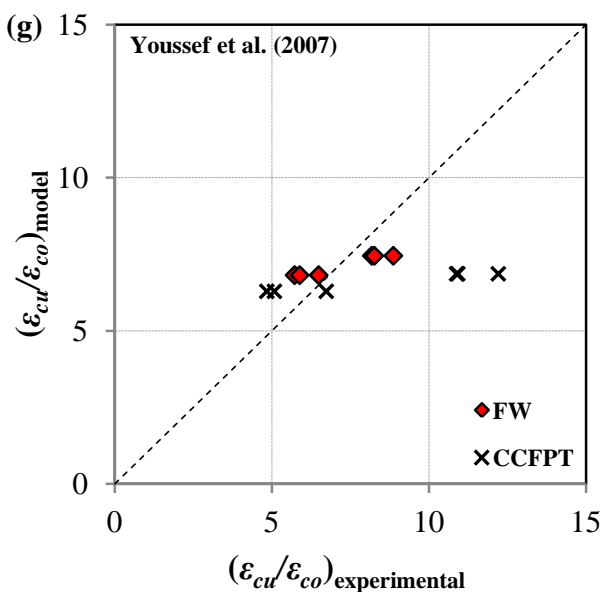

Fig 14. (continued) 